\title{
Characterizing, controlling and eliminating residual malaria transmission
}

\author{
Gerry F Killeen ${ }^{1,2}$
}

\begin{abstract}
Long-lasting insecticidal nets (LLINs) and indoor residual spraying (IRS) interventions can reduce malaria transmission by targeting mosquitoes when they feed upon sleeping humans and/or rest inside houses, livestock shelters or other man-made structures. However, many malaria vector species can maintain robust transmission, despite high coverage of LLINs/IRS containing insecticides to which they are physiologically fully susceptible, because they exhibit one or more behaviours that define the biological limits of achievable impact with these interventions: (1) Natural or insecticide-induced avoidance of contact with treated surfaces within houses and early exit from them, thus minimizing exposure hazard of vectors which feed indoors upon humans; (2) Feeding upon humans when they are active and unprotected outdoors, thereby attenuating personal protection and any consequent community-wide suppression of transmission; (3) Feeding upon animals, thus minimizing contact with insecticides targeted at humans or houses; (4) Resting outdoors, away from insecticide-treated surfaces of nets, walls and roofs. Residual malaria transmission is, therefore, defined as all forms of transmission that can persist after achieving full universal coverage with effective LLINs and/or IRS containing active ingredients to which local vector populations are fully susceptible. Residual transmission is sufficiently intense across most of the tropics to render malaria elimination infeasible without new or improved vector control methods. Many novel or improved vector control strategies to address residual transmission are emerging that either: (1) Enhance control of adult vectors that enter houses to feed and/or rest by killing, repelling or excluding them; (2) Kill or repel adult mosquitoes when they attack people outdoors; (3) Kill adult mosquitoes when they attack livestock; (4) Kill adult mosquitoes when they feed upon sugar or; (5) Kill immature mosquitoes in aquatic habitats. To date, none of these options has sufficient supporting evidence to justify full-scale programmatic implementation. Concerted investment in their rigorous selection, development and evaluation is required over the coming decade to enable control and, ultimately, elimination of residual malaria transmission. In the meantime, national programmes may assess options for addressing residual transmission under programmatic conditions through pilot studies with strong monitoring, evaluation and operational research components, similar to the Onchocerciasis Control Programme.
\end{abstract}

Keywords: Malaria, Residual transmission, Vector control, Anopheles, Mosquito, Elimination

\section{Background}

Although hundreds of Anopheles species have been described worldwide, certain biological and environmental factors distinguish a small subset of a few dozen that actually mediate transmission of Plasmodium parasites to humans in the wild [1,2]. First, only a subset of Anopheles species are physiologically competent vectors, meaning that they can support parasite development all the way

\footnotetext{
Correspondence: gkilleen@ihi.or.tz

IIfakara Health Institute, Environmental Health and Ecological Sciences Thematic Group, Ifakara, Morogoro, United Republic of Tanzania ${ }^{2}$ Liverpool School of Tropical Medicine, Vector Biology Department, Pembroke Place, Liverpool, UK
}

from gametocytes through to sporozoites that are infectious to humans, even if that only occurs under artificial experimental conditions [3]. Second, a physiologically competent vector can only transmit malaria outside a laboratory if it actually bites humans and survives long enough in the wild for sporogonic development of parasites to be completed [2-4]. The survival and reproduction of mosquitoes, as well as sporogonic development of parasites within their bodies, are both heavily dependent upon temperature, humidity and rainfall, so malaria transmission is most widespread and intense in the warmer, wetter regions of the tropics $[5,6]$. However, the specific

\section{Biomed Central}


behaviours exhibited by each distinct vector population in a given locality are not only important determinants of their vectorial capacity to mediate malaria transmission $[1,2,7]$ but also their vulnerability to control or even elimination [8-13].

Feeding upon humans as a driver of malaria transmission and intervention impact

Plasmodium vivax and Plasmodium falciparum account for the vast majority ( $>90 \%$ ) of human malaria infections worldwide and both can only be transmitted from one human to another via mosquitoes [5,6]. The entire infectious reservoir for these hugely important pathogens is to be found exclusively in humans, so their transmission requires that a mosquito must bite at least two people in its lifetime. Sustained local transmission therefore requires that local Anopheles mosquitoes are not only physiologically competent and survive long enough for complete sporogonic development of malaria parasites within their bodies, but also that they feed at least occasionally upon humans.

Malaria transmission intensity can be measured as the entomological inoculation rate (EIR), expressed as the number of times per year an individual human resident is bitten by mosquitoes with infectious sporozoites in their salivary glands. EIR increases approximately exponentially as the proportion of blood meals that a vector population obtains from humans increases (Figures $1 \mathrm{~A}$ and 1B), so the distribution of exceptionally high transmission intensities across equatorial Africa and some parts of the Pacific may be readily explained by the presence of Anopheles species that rely almost exclusively upon humans for blood (Figure 2). However, it is also critical to note that where a vector is heavily reliant upon human blood, it will often be consequently vulnerable to population control with indoor residual spray (IRS) or long-lasting insecticidal net (LLIN) products designed to kill mosquitoes when they encounter people or houses (Figures 1A and 1B) [10-15].

\section{Targeting stereotypical indoor resting and feeding behaviours of human-specialized Anopheles}

Given the importance of feeding upon humans as a determinant of malaria transmission (Figures 1 and 2), it is unsurprising that the most anthropophagic (predominantly feed upon humans) vectors are by far the best studied. It is also understandable that the specialized behavioural adaptations, which many of them have in common, have dominated thinking about malaria transmission and vector control for decades. Many of the most regionally important vectors of malaria, like Anopheles gambiae, Anopheles arabiensis and Anopheles funestus from Africa [16], Anopheles stephensi, Anopheles culicifacies and Anopheles punctulatus from Asia [17,18], or Anopheles darlingi,

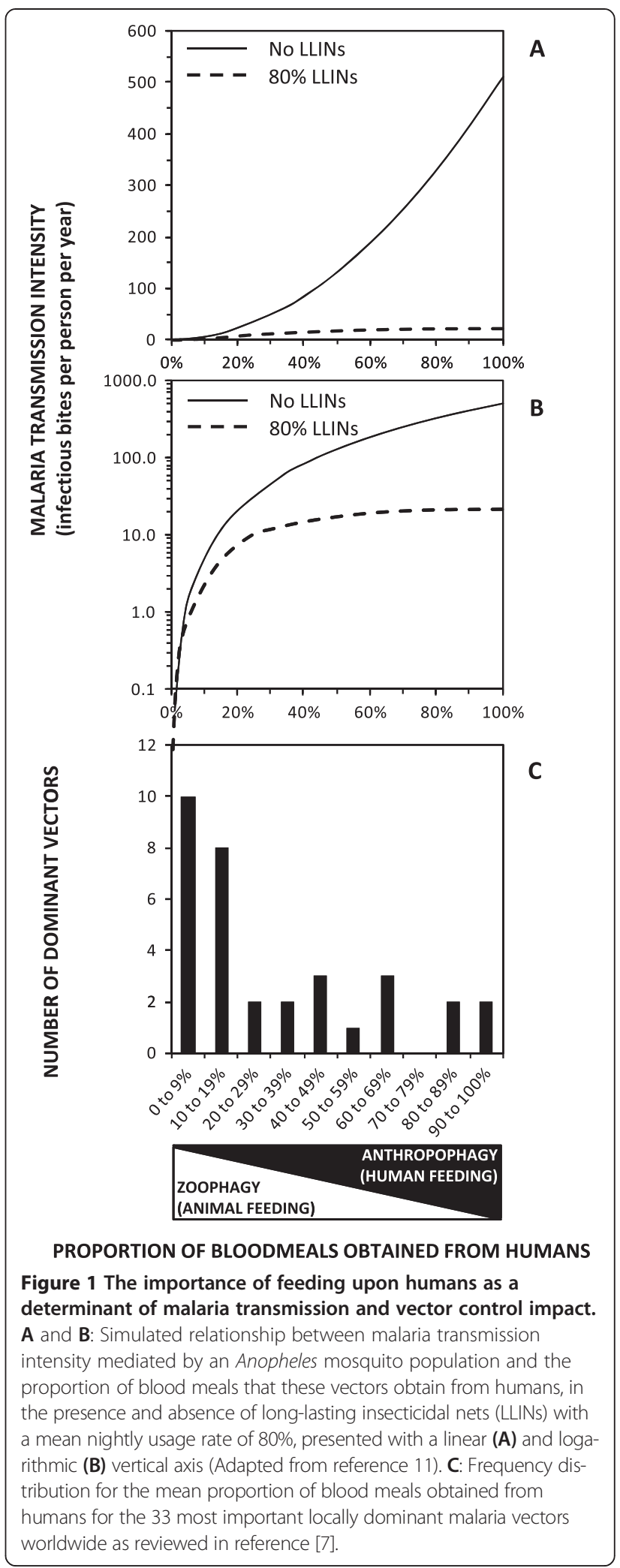

Anopheles punctimacula, Anopheles nunetzovari (species B or C) and Anopheles albimanus from Latin America $[19,20]$ prefer to feed in the middle of the night when 


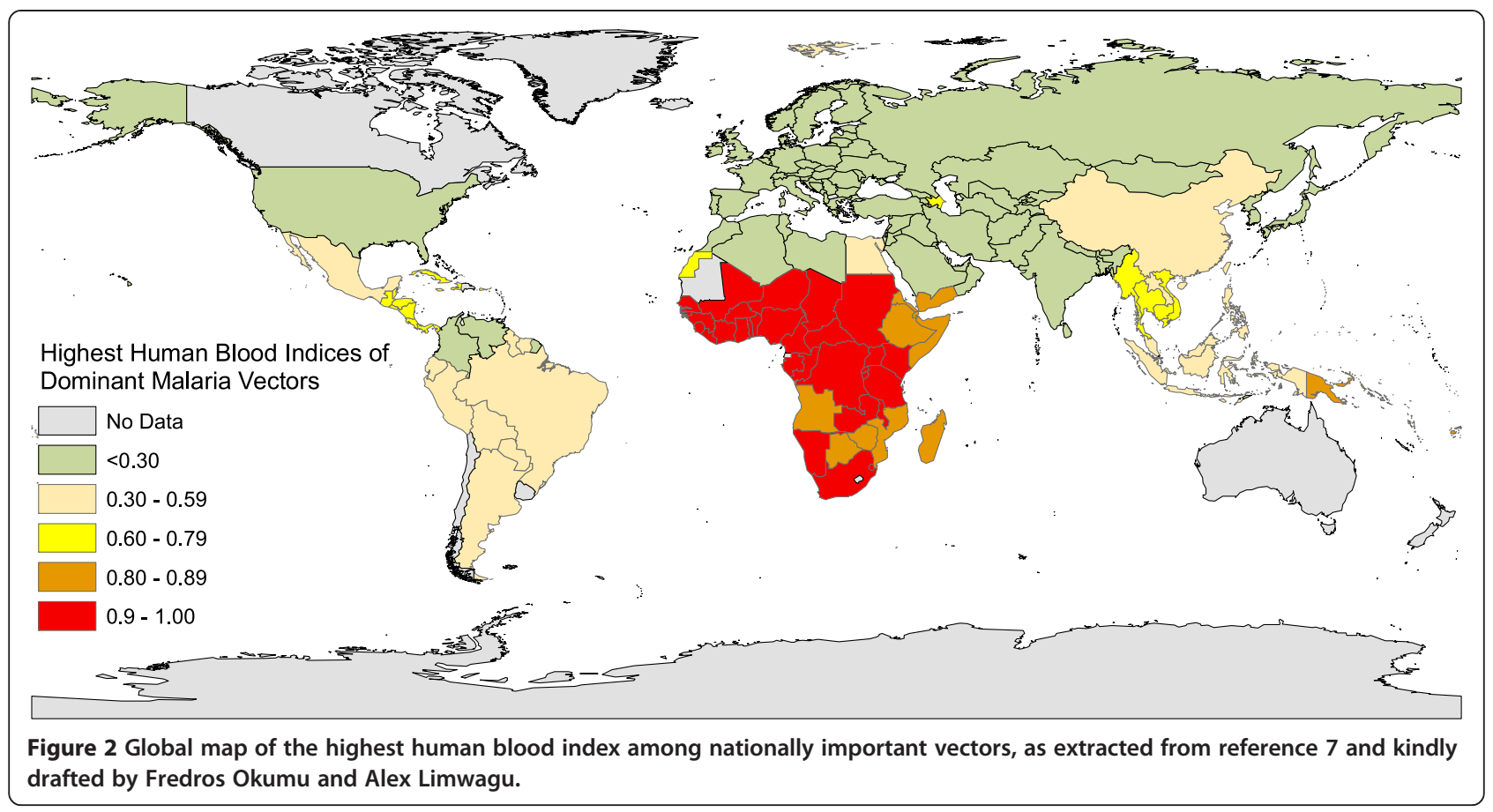

most humans are typically asleep, immobile and vulnerable to attack. Feeding indoors at night is, therefore, the behaviour that is targeted by use of LLINs to protect sleeping humans.

Indoor feeding is then often conveniently followed by resting within the same sheltered domestic structure for one or two nights while the blood meal is digested and eggs are developed. Applications of insecticides to houses by IRS, to kill mosquitoes resting on inner surfaces of the walls and roof after they have fed upon the human occupants, is therefore a highly effective strategy for controlling populations of vectors that rest indoors as a matter of preference.

The success of LLINs and IRS in combating malaria transmission by stereotypical vectors which feed and rest indoors is well established [21,22]. Even imperfect coverage of entire human populations with LLINs and IRS can have massive benefits for all members of malaria-afflicted communities, including those whose houses and sleeping spaces are not directly protected [23]. This community-wide mass effect occurs because those who are directly protected actually kill mosquitoes when they attempt to feed, so that vector survival rates and population densities are reduced, resulting in far fewer mosquitoes living long enough to mediate transmission between humans (Figure 3) [23]. Furthermore, LLINs and IRS can have a surprisingly dramatic impact on overall population size of stereotypical vectors that depend heavily upon feeding on humans and resting inside houses [13]: Entire vector populations may be eliminated, or at least negated as a cause of malaria, including documented examples for $A n$. gambiae and An. funestus in Africa, An. darling and An. nuneztovari in Latin America, and An. punctulatus as well as Anopheles koliensis in the Pacific [13].

\section{Persistence of residual transmission after scale up of LLINs and IRS: failure or limitation?}

Despite the impressive successes that have been achieved by targeting stereotypical vectors that feed and rest indoors with IRS and LLINs, complete elimination of malaria has rarely been achieved outside of areas that had marginal transmission levels to begin with $[13,24,25]$. There are fundamental limits to how much impact even the best implemented LLIN or IRS programmes can achieve in most tropical settings (Figure 4A) and it is essential to recognize that this phenomenon is normal and has been repeatedly reported from a variety of settings over the course of the last half century [13,26-30]. It is crucial to distinguish between such fundamental limitations of a given vector control strategy that has incomplete but nevertheless valuable and stable levels of impact that may be sustained over the long term (Figure 4A), and a genuine failure of an intervention programme that enables the vector population and malaria transmission to rebound (Figure 4B) [28,29,31].

While rebounding vector populations and malaria transmission intensities have been most commonly associated with failures of implementation and funding for vector control programmes, the emergence of physiological 


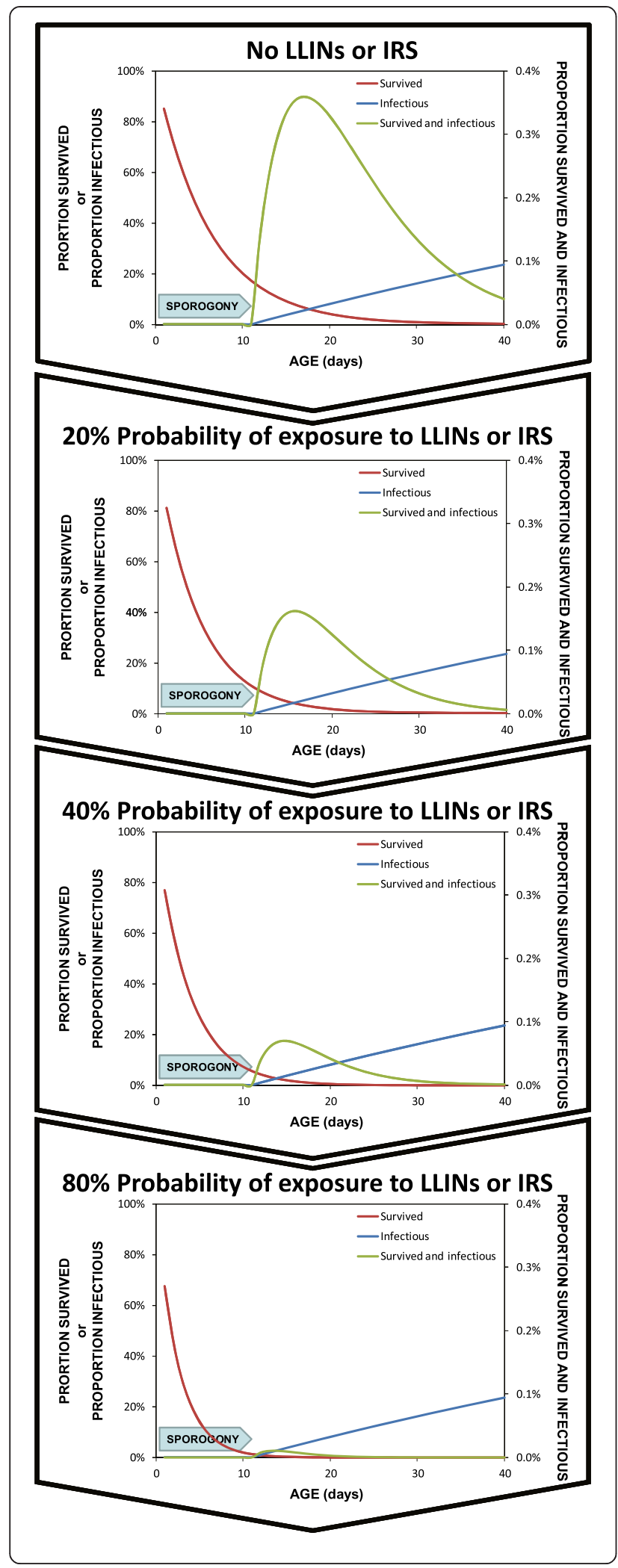

Figure 3 Progressive dramatic reduction of mosquito survival and infection probability as an increasing proportion of available blood meals are covered with LLINs or IRS. The probability curves presented represent the outputs of simulations implemented exactly as previously described [14] at 0, 20,40 and $60 \%$ biological coverage of all available blood resources $[10,13]$ with LLINs that kill $60 \%$ of all mosquitoes encountering them.

resistance to insecticides within these recovering mosquito populations has also been implicated [32]. Physiological resistance of mosquitoes to insecticides, resistance of policy makers to funding support, and resistance of the general public to interventions, are all widely accepted as important causes of vector control programme failure and have been reviewed in detail elsewhere [33]. However, it is less commonly understood that the fundamental limits of what can be achieved with IRS, LLINs, or indeed any other vector control strategy, are primarily defined by the behavioural traits of mosquitoes [13,19,26-30,34-36].

It is also extremely important to understand that many of the behavioural traits which allow residual populations of vector mosquitoes to survive and persistently transmit malaria despite high coverage of LLINs or IRS, appear to have always been present in these populations [13,26-29]. As such, they are better described as pre-existing behavioural resilience (Figure 4A), rather than emerging resistance in the strict sense (Figure 4B) $[28,29]$. While the possibility that true behavioural resistance may emerge in response to intervention pressure upon vector populations cannot be ignored $[30,37,38]$, no clear-cut instance of this phenomenon has been documented in the field $[26,28]$. While many instances of apparently altered or atypical patterns of mosquito behaviour have been reported, and some of these are difficult to explain without assuming the emergence of behavioural resistance [38], it is technically difficult to unambiguously attribute these to the emergence of heritably altered preference traits. Instead, these observations of altered mosquito behaviours may well arise instead from either (1) altered taxonomic composition of the vector population due to differential suppression of various species and sub-species taxa as a result of their varying degree of behavioural suitability to control with IRS or LLINs, or (2) altered expression of innately flexible behaviours by mosquitoes in response to the altered patterns of blood and resting site resource availability in their environment following IRS or LLIN scale up $[26,28]$. However, regardless of whether these behaviours reflect the selection of new heritable resistance traits, the altered expression of pre-existing resilience traits, or a combination of both, the fact remains that they will have to be deliberately and specifically targeted with new vector control tools to achieve malaria elimination $[37,38]$. 


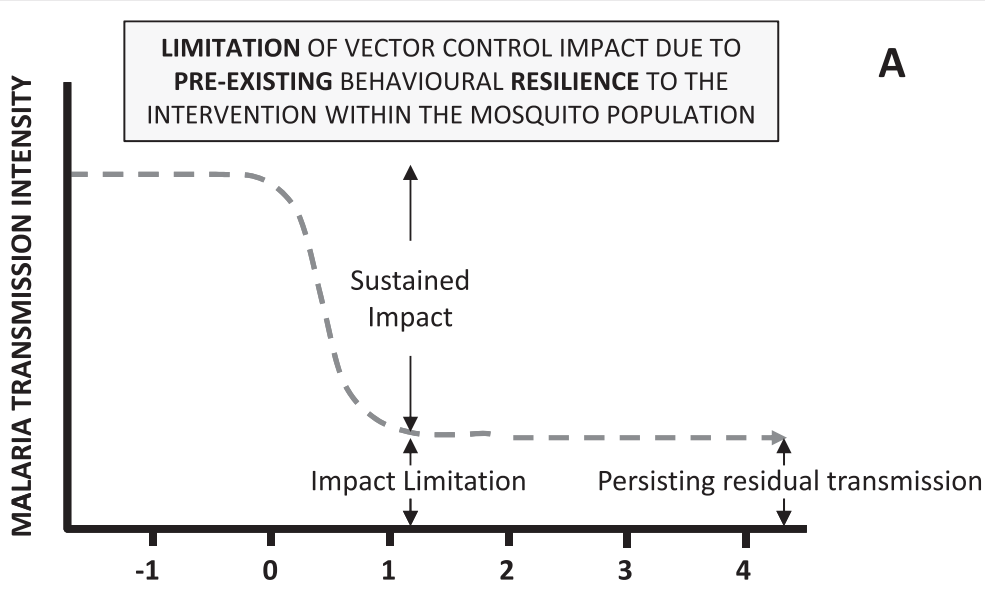

YEARS SINCE INTRODUCTION OF AN INTERVENTION
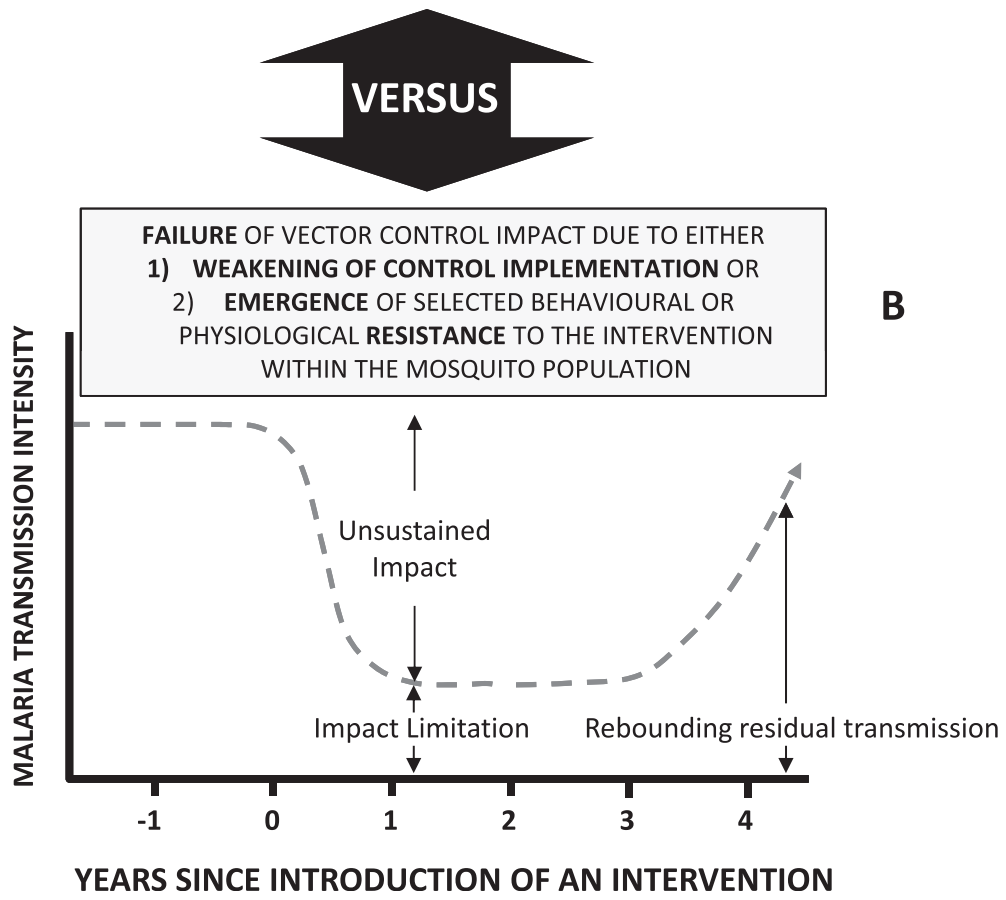

Figure $4 \mathrm{~A}$ schematic illustration of the differing trajectories of impact of an intervention upon malaria transmission by a vector population under the distinctive scenarios of either (A) Stable limitation of sustained impact arising from expression of pre-existing behavioural traits within a resilient vector population, or (B) Failure of impact and resurgence of malaria transmission when, either intervention programme implementation quality and coverage weakens, or selected behavioural or physiological traits emerge within an increasingly resistant, rebounding vector population [31].

Beyond the stereotype: Mosquito behaviours that limit the impact of LLINs and IRS

Unfortunately, the small number vectors that feed predominantly on humans are responsible for such a disproportionately large share of the world's malaria burden (Figures 1 and 2) that their specific behavioural adaptations, to attacking sleeping humans inside houses and then resting there, have been widely and inaccurately stereotyped as typical of malaria vectors in general. However, Anopheles species that exhibit high vectorial capacity, but also high susceptibility to control or even elimination with LLINs and IRS, are the exceptions rather than the rule among malaria vectors. Broadly speaking, known behaviours that buffer mosquito populations and malaria transmission against IRS and LLINs fall into two main categories: 1) Insecticide contact avoidance and early-exit behaviours that minimize the exposure hazard faced by vectors that preferentially feed indoors, and, 2) Animal-feeding and outdoor-feeding behavioural preferences that allow mosquitoes to minimize 
contact with insecticides targeted at humans and houses altogether.

\section{Insecticide avoidance and early-exit behaviours among indoor-feeding vectors}

Several vector species appear to have always exhibited a pre-existing tendency to exit houses soon after entering, and this represents an important form of behavioural resilience that receives inadequate attention [19,39-41]. However, it has long been known that such insecticideavoidance behaviours can also be induced or exacerbated by irritant or repellent active ingredients that can enhance personal protection afforded by a protective measure but may also undermine potentially greater impact upon vector populations that normally feed indoors upon humans [42-44]. Recent simulation analyses suggest that expression of such avoidance behaviours, which allow vectors to either avoid, or enter but then safely leave, houses protected by LLINs and/or IRS, actually represent an optimal survival strategy for mosquitoes because it allows them to maximize their feeding probability by continuing to forage until they find unprotected hosts [38] (Figure 5). It is therefore understandable that some remarkably robust populations of An. arabiensis [45], a species known to be capable of avoiding insecticide exposure when they enter houses [39-41], have retained their historically strong preferences for feeding indoors despite exposure to high levels of LLIN usage by humans for over a decade [46].

Vectors that enter but then rapidly exit from human habitations Several important vector species around the world, such as An. arabiensis from Africa [39-41] or $A n$. darlingi, An. punctimacula and An. nunetzovari (species B or C) from Latin America [19], enter houses but then rapidly exit again, regardless of whether or not they have successfully fed upon the human occupants. Even when such vectors make direct contact with an insecticidetreated wall [19] or blood host [47], they rarely do so for longer than one or two minutes so that fatal exposure is avoided. Interestingly, this particular combination of behaviours was considered the most important obstacle to elimination of malaria from the Americas with IRS during the Global Malaria Eradication Programme [19] and the same is probably true in many parts of east Africa today where $A n$. arabiensis [39-41] is often responsible for most of the persisting residual transmission following successful scale up of LLINs [45,48-50].

Induced vector avoidance of contact with repellent or irritant insecticides It has long been known that even mosquitoes which are normally very susceptible to control with LLINs or IRS, due to the fact that they usually feed and rest indoors, may choose to curtail or avoid periods of physical contact with insecticides if they can detect them with their sensory organs [42-44]. Such stimulant insecticides artificially induce or exacerbate early exit behaviours, ultimately attenuating mosquito exposure to lethal doses [14,15,42-44,51]. Behaviourmodifying insecticides which require direct physical contact with a mosquito to induce an avoidance response are known as contact irritants, while those that the mosquito can sense in the air at a distance from the treated surface, and then choose to avoid contact with, are known as spatial repellents [51,52]. Many vector mosquito species may feed and rest indoors in the absence of LLINs or IRS with such irritant or repellent insecticides, but the presence of these active ingredients may induce them to leave houses prematurely or even avoid entering in the first place $[26,43,51,53]$.

While many manufacturers emphasize that their products combine behaviour-modifying repellent and irritant properties with contact toxicity, this ignores the fact that these three actions occur sequentially and competitively in that order $[14,15,51]$. No individual mosquito approaching a protected human can be classified as having been affected by two or more of these actions: By definition, an insecticide can only kill a mosquito if it is not first irritated upon contact, and neither of these outcomes is possible if it is repelled before making contact $[51,54]$. A given LLIN or IRS product may be optimized to maximize the irritant and repellent actions of subtoxic doses of the active ingredient, thereby increasing the level of personal protection that is most important for preventing transmission by mosquitoes that only feed occasionally upon humans $[10,11]$, especially if they do so outdoors $[8,10,15]$. However, this choice will reduce exposure of mosquitoes to toxic doses of the active

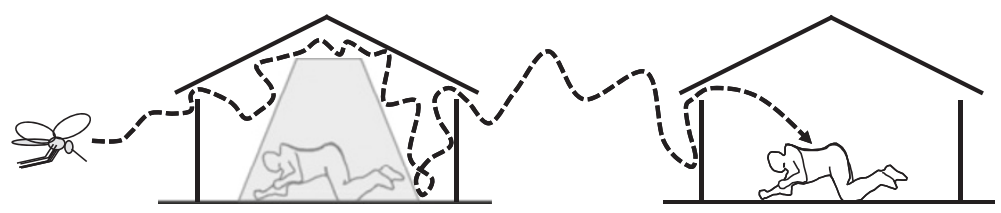

Figure 5 A schematic illustration of how mosquitoes may survive despite high coverage of long-lasting insecticidal nets or indoor residual spraying by entering, but then rapidly leaving houses protected with LLINs or IRS without exposing themselves to lethal doses of the active ingredients, and then continuing to forage until an unprotected blood host is found [38-41]. 
ingredient that can kill them outright and therefore undermines the massive community-level protection that can be achieved through vector population suppression where vectors are heavily dependent upon human blood for their survival $[8,10,14,15,51,55]$. In summary, these alternative modes of action must be traded off against each other: While a contact toxin may have no advantage over a behaviour-modifying irritant or repellent where local vectors populations are not dependent on human blood for their survival $[8,10,11]$, in situations where vectors predominantly feed upon people indoors and can be killed inside houses by toxic insecticides delivered as LLINs or IRS, supplementing these with any repellent or irritant action may ultimately undermine their potential to control $[8,10,14,15,51,55]$ or even eliminate [13] such stereotypically synanthropic vectors.

It is particularly notable that the principles underlying the necessity to choose between toxic versus irritant and repellent modes of action were widely accepted during the era of the Global Malaria Eradication Programme (GMEP) [42-44]. Indeed, by the end of the GMEP, it was already recognized that implementing IRS with DDT, which is known to be both repellent and irritant $[54,56]$, generally had less impact than implementing IRS with insecticides that lacked these properties [44]. In fact, the main reasons why DDT was often selected as the active ingredient of choice were its affordability and longer duration of residual activity [44]. It is therefore timely to note that these principles were played out again in recent experimental hut trials in which IRS with DDT slightly attenuated the toxic effects of one pyrethroid-treated net product when the two were combined in the same hut $[40,41]$. It is also noteworthy that the An. arabiensis population that these IRS-LLIN combinations were evaluated against already exhibited early exiting behaviour even in the absence of insecticides [40,41]. While new vapour-phase repellents to prevent transmission exposure outdoors are clearly essential, they should be applied cautiously inside houses wherever indoorfeeding or indoor-resting mosquitoes with strong preferences for human blood and high vectorial capacity exist $[8,10,14,15,51]$. In such circumstances, purely toxic insecticide formulations delivered to houses, possibly in the form of IRS and LLINs, are likely to achieve greater impact $[8,10,14,15,51]$.

\section{Behavioural preferences for feeding outdoors and upon animals}

The majority of malaria vector species worldwide can be described as zoophagic because they actually feed predominantly upon animals (Figures $1 \mathrm{C}$ and 2). Since they rarely bite humans, they are correspondingly less efficient at transmitting malaria (Figures $1 \mathrm{~A}$ and $1 \mathrm{~B}$ ). However, these less potent vectors are often difficult to control with
LLINs or IRS, not only because they usually feed upon unprotected animals (Figures 1A and 1B), but also because, they usually prefer to feed at dusk and dawn (Figure 6) when most of their human victims are outdoors, beyond the protective reach of these prevention measures. Zoophagic mosquitoes with moderate vectorial capacity, most of which primarily feed and rest outdoors, are widespread throughout the tropics (Figures $1 \mathrm{C}$ and 2). These species often respond poorly to LLIN or IRS interventions because the technologies are designed to target the stereotypical behaviours of the smaller number of more potent, human-specialized species (Figure 1) that mediate most, but by no means all, of the global malaria burden (Figure 2).

Vectors that feed upon animals Many mosquitoes are highly specialized in terms of their preferred blood sources [57], and exhibit enormous diversity of preference even between morphologically identical members of a single species complex [58-61]. Humans represent only one of the many vertebrates Anopheles have adapted to exploit [57] and the vast majority of malaria vectors feed primarily on animals (Figures $1 \mathrm{C}$ and 2). EIR levels as low as 0.1 infectious bites per person per year are typically sufficient to sustain endemic populations of malaria parasites [62-64] so a mosquito species may be capable of sustaining endemic malaria transmission even if it feeds only rarely upon humans (Figure $1 \mathrm{~A}$ and $\mathrm{B}$ ). So while a small proportion of the world's overall malaria burden is caused by Anopheles which prefer to feed upon animals, these comprise the majority of all malaria vectors

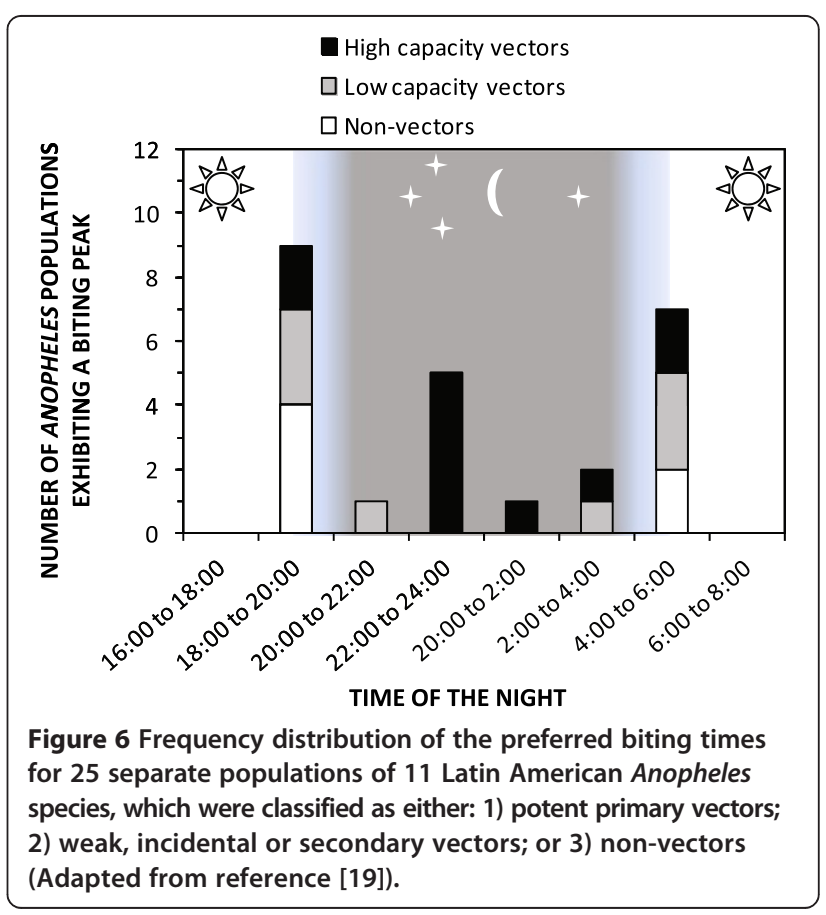


worldwide (Figures 1C) and affect the majority of the global at-risk human population who live outside of Oceania or Africa south of the Sahara [5,6] (Figure 2).

Most of the world's at-risk population [5,6] is therefore exposed to limited, but nevertheless self-sustaining, malaria transmission by mosquitoes which have moderate vectorial capacity since potentially infectious humans contribute only a minority of the blood meals they rely upon to survive and reproduce (Figure 2). While the malaria transmission caused by this near-ubiquitous plethora of zoophagic vectors occurs at relatively modest intensities, it is also relatively unresponsive to control with measures that target human blood sources, such as IRS and LLINs (Figure 1A and B). While high coverage of these measures can achieve useful community-wide reductions of malaria transmission by preventing human-vector contact $[10,11]$, the actual impact upon population density and survival of vectors is likely to be negligible given that these mosquitoes obtain most of the blood they need from animals (Figure 1A and 1B). This disconnect, between targeting IRS and LLINs at the humans who need to be protected and not at the animals that mosquitoes depend on for survival, creates a gap in protective coverage of the blood resources that actually sustain the vector population $[8,10,11,13]$. High coverage of all these blood resources with interventions that render them hazardous to mosquitoes is required if population control is to be achieved, rather than merely direct personal protection of the subset that humans represent $[8,10,11,13]$.

Vectors that feed on people when they are active outdoors Even amongst the stereotypically nocturnal major vectors of Africa, which overwhelmingly prefer to feed at night when people are asleep [16], a small but important portion of feeding activity does occur at dawn and dusk. While this represented a minor fraction of historical malaria transmission in unprotected African populations, it now typically accounts for approximately half of all transmission exposure to residual vector populations for individuals protected against most indoor exposure by LLINs [29] (Figure 7). Furthermore, several recent reports of atypical or altered biting patterns by these same vector species suggest that higher proportions of transmission now occur outdoors in the evenings and early mornings [50,65-70] so the majority of residual exposure of net users most probably occurs outdoors in many African settings.

Beyond Africa, the four major Latin American vectors which were historically implicated in the failure of IRS to eliminate malaria from Colombia $[19,20]$ predominantly fed upon humans when they slept indoors at night (Figure 8), to essentially the same extent as stereotypical African vectors (Figure 7). However, in this historical example, at least half of residual transmission by all four of these Latin American species would also have occurred outdoors if all residents had used a modern LLIN (Figure 8).

While Anopheles dirus in south-east Asia can exhibit similarly stereotypical nocturnal, indoor-feeding behaviour, this is unusual amongst vectors within the region (Figure 9) and there are numerous other examples of An. dirus mostly feeding outdoors, much earlier in the evening [73]. Similarly to their African counterparts, at least half of the exposure of residents who use LLINs to such stereotypically nocturnal, indoor-feeding vectors populations where they occur in south-east Asia occurs while they are outdoors (Figure 9). This is particularly worrying in relation to An. dirus, the most important vector in the greater Mekong region where containment of growing parasite resistance to artemisinin-based drugs will most probably require elimination of transmission at sub-regional level [74].

By comparison with these stereotypical anthropophagic Anopheles that are all known to be associated with intense transmission of malaria, species with lower vectorial capacity, most of which are more inclined to feed upon animals, typically exhibit no such adaptation to feeding in the middle of the night when people are asleep. Instead, such crepuscular vectors feed at dawn and/or dusk, or during the hours of darkness immediately before dawn and after dusk (Figure 6) when most people are awake and active, and it is impractical to protect them with LLINs. Feeding upon exposed humans at dawn and dusk predominantly occurs outdoors, and is consequently usually followed by resting outdoors, beyond the reach of IRS.

As just one example of a vector that often departs from the stereotype of indoor feeding and resting, several reports of $A n$. dirus feeding outdoors in the evening [73] indicate that the only published example from which exposure distribution could currently be calculated (Figure 9) may not be fully representative of the species in general. Furthermore, remarkably high proportions of malaria transmission occur outdoors across all the other major regions of Asia (Figure 9). In the absence of any preventative measure, approximately half of transmission by all vectors in the south, south-east and Pacific regions of Asia, other than Anopheles culicifacies, occurs outdoors so provision of either LLINs or IRS is unlikely to directly protect against this fraction of exposure. Even for An. culicifacies, the most endophagic vector on the continent, one fifth of exposure occurs outdoors for non-users of LLINs. Furthermore, for users of LLINs, remaining indoor exposure that nets cannot be expected to completely prevent, accounts for only one fifth of residual transmission by An. culicifacies, and less than one tenth of residual transmission by all the other Asian vectors described in Figure 9. It is also notable that apparently altered behaviours, presumably reflecting 


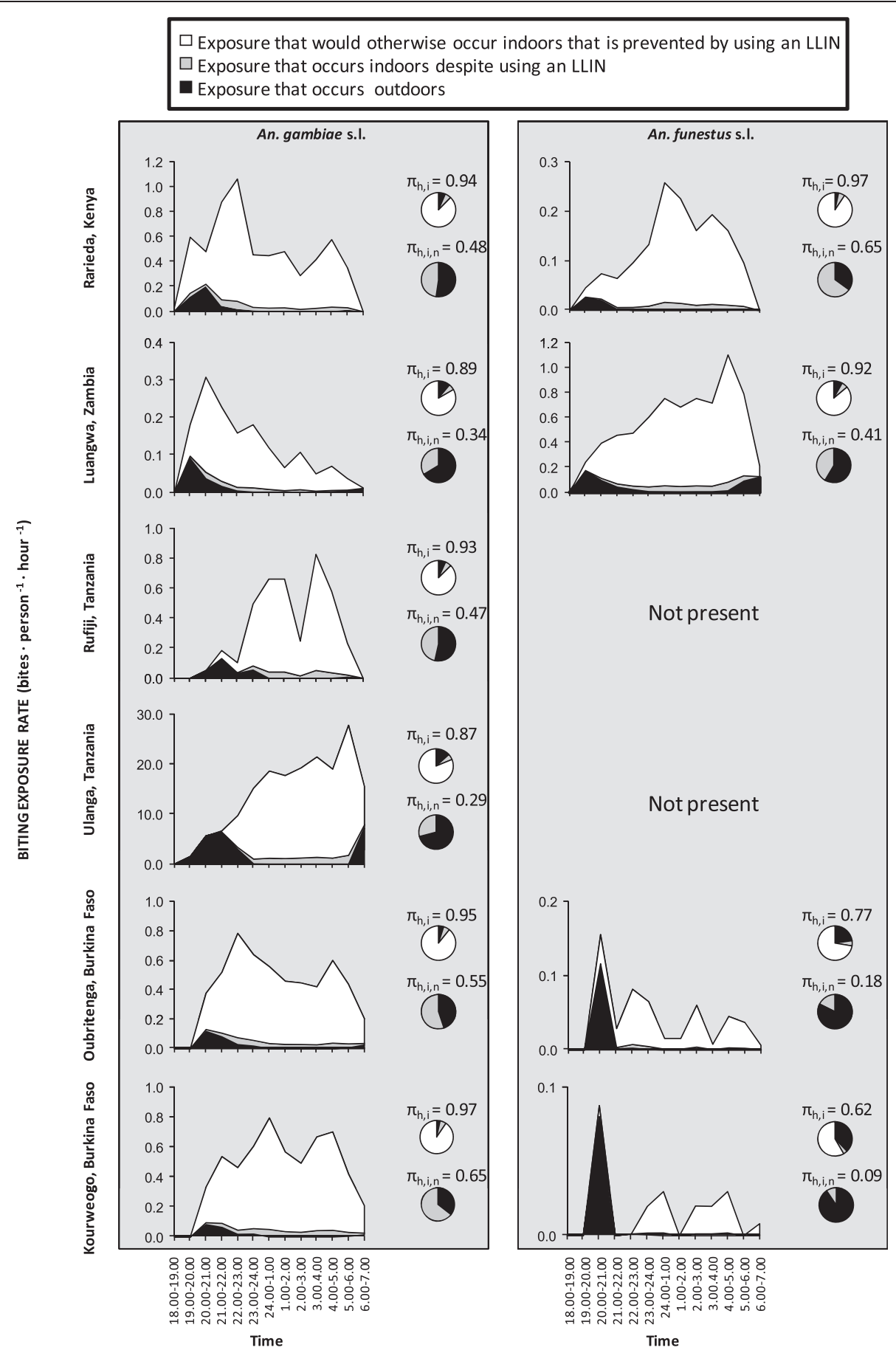

Figure 7 Estimates of the proportion of human exposure to African malaria vector populations that occurs indoors for both unprotected residents $\left(\pi_{h, i}\right)$ and users of long-lasting insecticidal nets $\left(\pi_{h, i, n}\right)$, from field sites across eastern, southern and western Africa [16], as previously calculated [71,72] and presented in summary form [29]. Original data kindly provided by Bernadette Huho, Olivier Briët, Aklilu Seyoum, Chadwick Sikaala, Nabie Bayoh, John Gimnig, Fredros Okumu, Diadier Diallo, Salim Abdulla and Tom Smith.

behavioural resistance in the strict sense [38], have been observed on several occasions following implementation of IRS against these Asian vectors [26,73]. Clearly, any vector measure selected to complement LLINs as a means of providing direct personal protection must be feasibly applicable by human users outdoors, including during periods when they are active, if it is to confer any meaningful incremental impact.

The major vectors of south Asia only occasionally feed upon humans [7], and largely do so outdoors [79], so the 
$\square$ Exposure that would otherwise occur indoors that is prevented by using an LLIN

$\square$ Exposure that occurs indoors despite using an LLIN

Exposure that occurs outdoors

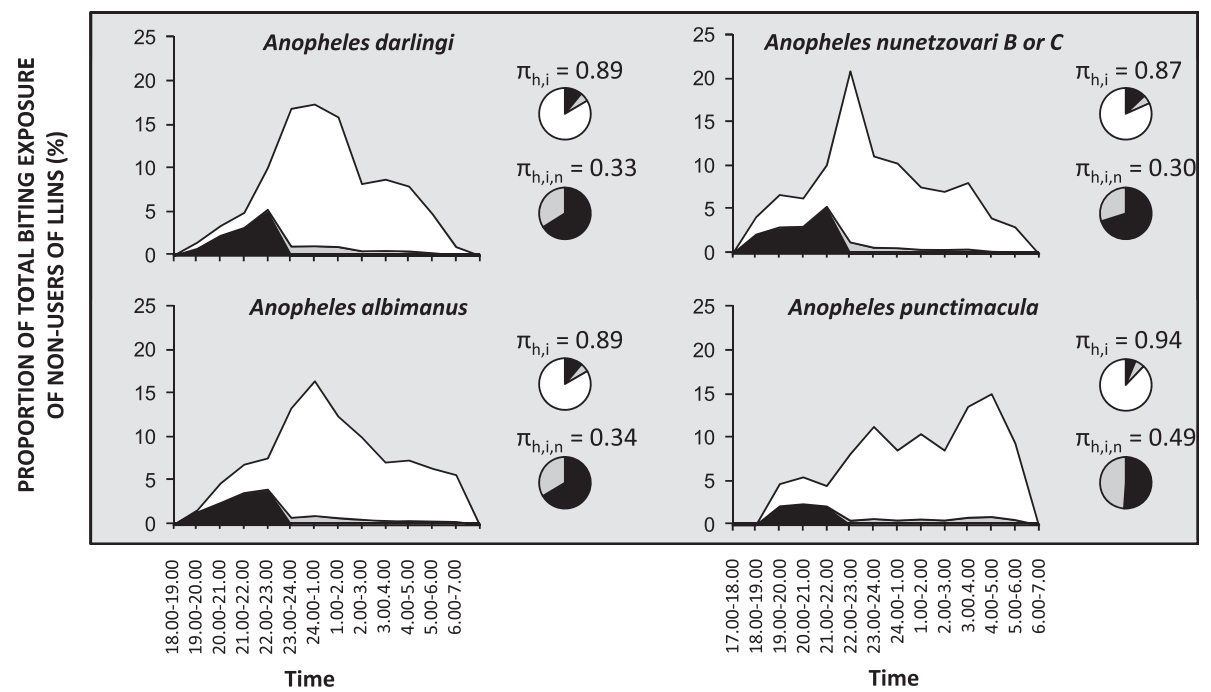

Figure 8 Historical estimates of the proportion of human exposure to Latin American malaria vector populations in Colombia that would have occured indoors for both unprotected residents $\left(\pi_{h, i}\right)$ and users of modern long-lasting insecticidal nets $\left(\pi_{h, i, n}\right)$, calculated as originally described $[19,20]$, except for the breakdown of indoor exposure into the fractions that would and would not be prevented by net use [71,72].

maximum biological coverage of blood resources that can be achieved with LLINs appears negligible because it is viewed solely in terms of feeding behaviours alone (Figure 10). However, these major vectors are nevertheless remarkably susceptible to control with IRS [22], because they usually rest inside houses and cattle shelters after feeding [79]. This example illustrates just how important it can be to clearly identify and distinguish the specific blood, resting site, sugar, or larval habitat resource, or subsets thereof, that a given intervention actually targets and to quantify the rate at which it is utilized $[8,80]$. Such quantitative approaches to surveying mosquito resource utilization behaviour may be useful to distinguish: (1) scenarios in which LLINs or IRS may have little impact, so that alternative vector control strategies are desperately needed; and (2) scenarios such as the south Asian example outlined above, where IRS may be surprisingly effective so additional approaches may be viewed as complementary and secondary, rather than superior, primary alternatives $[8,80]$.

Quantifying the limits of biological coverage that are attainable with LLINs and IRS Achieving population control of malaria vectors, rather than merely personal protection of human individuals and communities, requires that reasonably high mosquito mortality rates are achieved, similar to those depicted at the bottom of Figure 3. However, delivering such a population control impact in practice requires high insecticide coverage of all blood sources, or all associated resting sites, rather than just the fraction represented by the human population [10]. It is, therefore, critical to conceptualize and quantify the influence of feeding upon animals and feeding or resting outdoors in terms of field-measurable, behaviourallydefined gaps in the de facto coverage of blood or resting site resources that IRS and LLINs achieve $[10,13]$. Indeed the natural limits of what is possible with LLINs, and to a lesser extent IRS, may be represented in terms of gaps in biological coverage of all blood resources $[8,13]$. Biological coverage may be plotted as the product of the proportion of blood meals obtained from humans and the proportion of human blood meals obtained indoors, both of which can be readily measured in the field, with the remaining uncovered proportions along each axis of the twodimensional plot representing the coverage gaps $[10,13]$. The data presented in Figures 1, 2, 7, 8 and 9 can therefore be used to illustrate the impressive extent of the biological coverage gaps caused by mosquitoes feeding upon animals, and upon humans when they are outdoors (Figure 10). Even in Africa, where the biological coverage limits of LLINs are generally quite high, it is notable that that the biological coverage gaps for An. arabiensis (18\%), often the most robust of the three most important vectors in the region, are more than twice as large as those for $A n$. gambiae (7\%) and An. funestus (6\%), which have both 


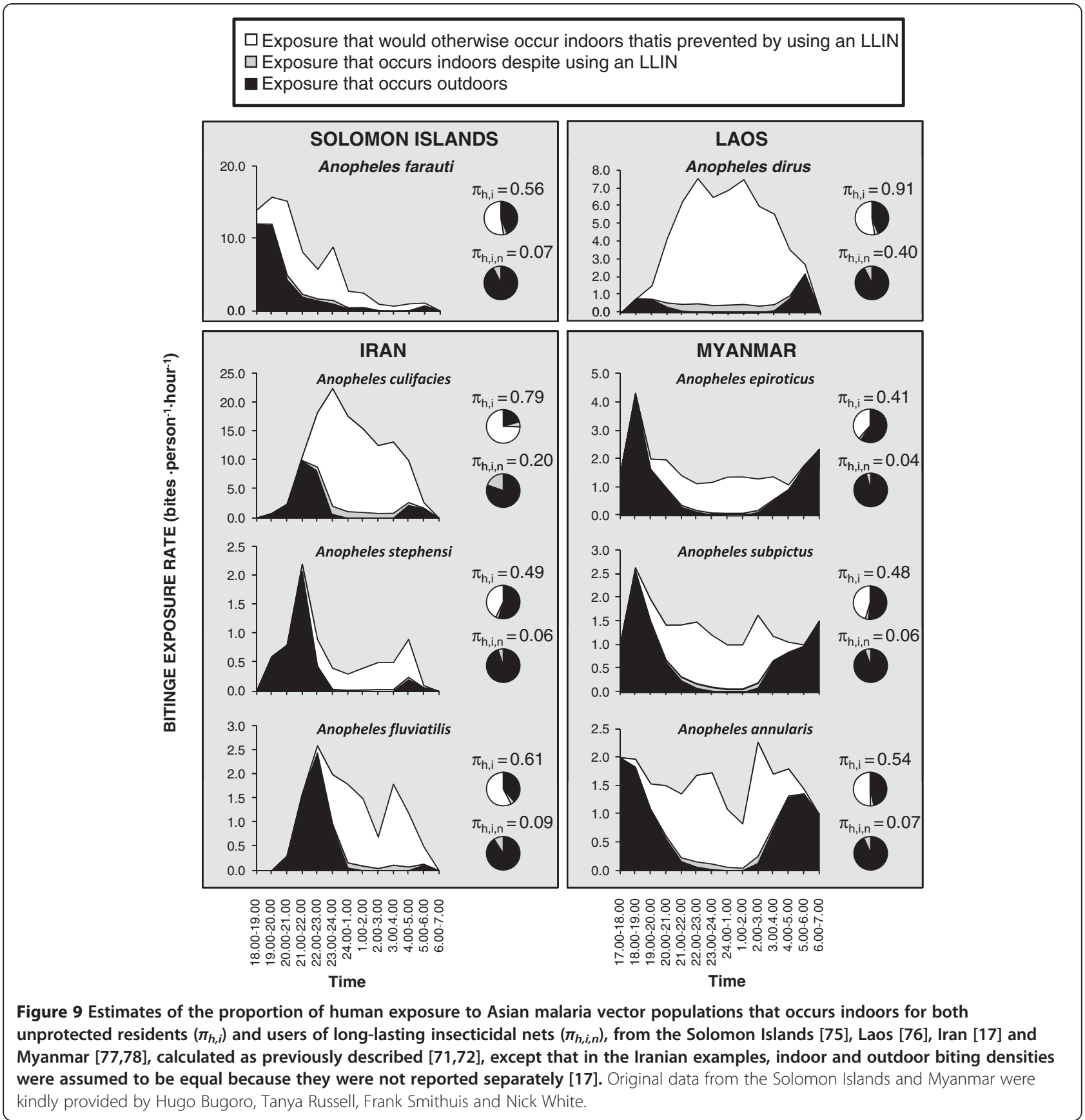

been eliminated, or almost eliminated, by LLINs or IRS on several occasions [13].

While estimates of biological coverage based on human blood utilization patterns may be relevant to IRS in the many settings in which vectors rest where they feed, they may be misleading where vectors feed indoors but rest outdoors or vice versa [8]. Improved entomological survey methods are therefore required to quantify vector utilization of treatable resting site surfaces so that similar, but more directly relevant, biological coverage limits can be estimated for IRS $[8,80]$.
The scale of the challenge presented by residual transmission

The best estimates to date all suggest that transmission of $P$. falciparum malaria only drops below self-sustaining levels at EIR values of less than 0.1 infectious bites per year [62-64,81], so historical values approaching 1000 infectious bites per year reported from several setting are approximately ten thousand times higher than those required to sustain a stable parasite population $\left(R_{0} \geq 10,000\right)$. Thus, even a $99 \%$ reduction of transmission by LLINs/IRS would only take control half way 


\section{EXAMPLES OF PREDOMINANTLY ANTHROPOPHAGIC AND ENDOPHAGIC VECTORS FROM SUB-SAHARAN AFRICA}

\section{Anopheles funestus}

$\left(C_{\mathrm{v}, \max }=0.92\right)$

$\pi_{\mathrm{h},}=0.94$

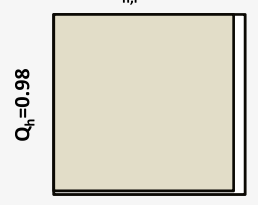

Anopheles gambiae

$\left(C_{v, \text { max }}=0.87\right)$

$\pi_{\mathrm{h}, \mathrm{i}}=0.93$

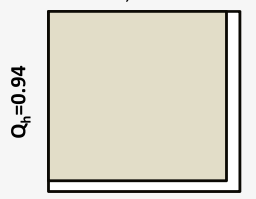

Anopheles arabiensis

$\left(C_{\mathrm{v}, \max }=0.71\right)$

$\pi_{\mathrm{h}, \mathrm{i}}=0.82$

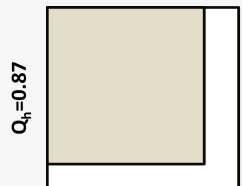

EXAMPLES OF INTERMEDIATE ZOOPHAGIC/ANTHROPOPHAGIC AND ENDO/EXOPHAGIC VECTORS FROM SOUTH-EAST ASIA AND OCEANIA ASIA

Anopheles epiroticus

$\left(C_{\mathrm{v}, \max }=0.25\right)$

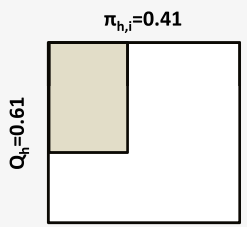

Anopheles farauti

$\left(C_{\mathrm{v}, \max }=0.37\right)$

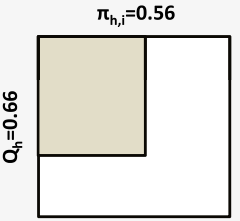

EXAMPLES OF MODERATELY TO STRONGLY ZOOPHAGIC BUT HIGHLY ENDOPHAGIC VECTORS FROM SOUTH-EAST ASIA AND LATIN AMERICA
Anopheles dirus
Anopheles darlingi
Anopheles nuneztovari
Anopheles albimanus
$\left(C_{\mathrm{v}, \max }=0.32\right)$
$\left(\mathrm{C}_{\mathrm{v}, \max }=0.41\right)$
$\left(C_{\mathrm{v}, \max }=0.19\right)$
$\left(C_{\mathrm{v}, \max }=0.09\right)$
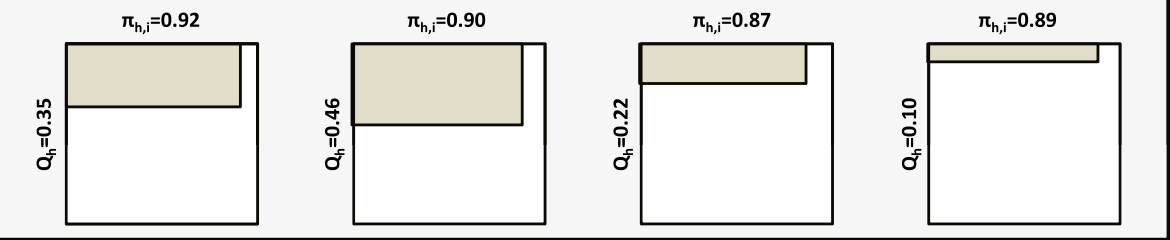

EXAMPLES OF STRONGLY ZOOPHAGIC AND EXOPHAGIC VECTORS FROM SOUTH ASIA

Anopheles culicifacies $\left(C_{v, \max }=0.04\right)$

$\pi_{\mathrm{h}, \mathrm{i}}=\mathbf{0 . 7 9}$

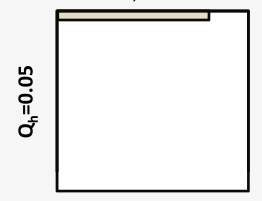

Anopheles stephensi

$\left(C_{v, \max }=0.01\right)$

$\pi_{\mathrm{h}, \mathrm{i}}=0.49$

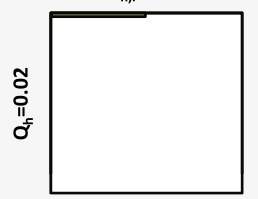

Anopheles fluviatilis

$\left(C_{v, \max }=0.02\right)$

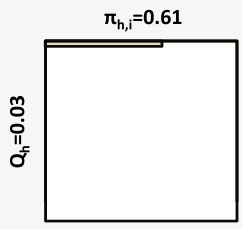

Figure $10 \mathrm{~A}$ graphic illustration of the estimated maximum achievable biological coverage of all blood resources $\left(\mathrm{C}_{\mathrm{v}, \text { max }}\right)$ utilized by the vector species described in Figures 1, 2, 7, 8 and 9, for which estimates of both the proportion of blood meals obtained from humans $\left(Q_{h}\right)$ and the proportion of human blood meals obtained indoors $\left(\pi_{h, i}\right)$ were available. The width of the grey rectangles relative to that of the white squares represents the limit of personal protection and derived community-wide reduction of mutual human-vector exposure, while their relative area represents the achievable limit of biological coverage of all blood resources that determines the extent to which the density and survival of the vector population can be controlled $[8,10,11,13]$. 
along the pathway to elimination and further reductions of similar magnitude would be required to destabilize $P$. falciparum parasite populations in such settings (Figure 11). Residual transmission can therefore be remarkably intense, especially in many parts of Africa and Oceania, where it can occur at intensities far in excess of the thresholds required to be self-sustaining, irrespective of how effectively LLINs, IRS and complementary interventions to diagnose and treat humans are applied $[26,28-30,35,36]$. Now that history has repeated itself, it must be accepted that these limitations are fundamental and biological in nature, rather than financial or operational [29]. Improved programmatic funding and effectiveness, to deliver better coverage of improved IRS or LLIN products, will not achieve elimination of malaria transmission from most settings because their fundamental limitations of impact are defined by vector behaviours that enable them to avoid fatal contact with these interventions [13,26-30,34-36]. Perhaps the most convincing proof of this principle lies in the exceptions: Iran [82] and Sri Lanka [83], for example, are both on the verge of elimination because their southern Asian vectors all predominantly rest indoors [79] and are therefore vulnerable to control with IRS [22], despite feeding largely upon animals [7] and often feeding outdoors on the important occasions when they do attack humans (Figure 9).

\section{Defining residual malaria transmission}

These well-established, fundamental and biological limitations of IRS and LLINs need to be openly and unambiguously acknowledged at all national and international levels of policy and practice. The term residual malaria transmission is therefore defined here as all forms of malaria transmission that persist after full universal coverage with effective LLIN and/or IRS interventions has been achieved.

New and improved vector control options for controlling and eliminating residual malaria transmission

In order to eliminate malaria from most endemic regions of the tropics, concerted investment is required, not only to sustain and consolidate recent gains with LLINs and IRS [33], but also to select, develop and rigorously evaluate supplementary vector control strategies that address residual transmission by deliberately

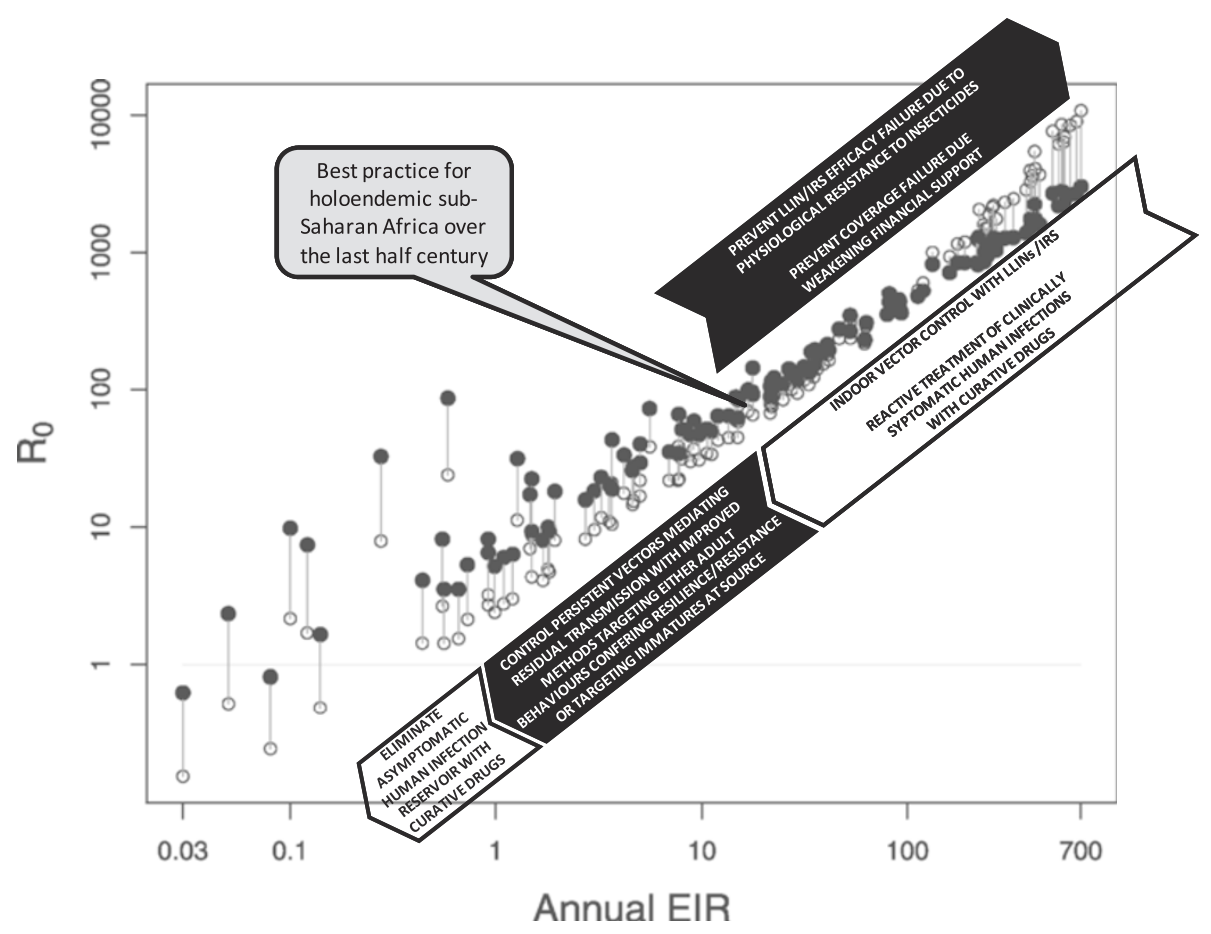

Figure 11 A schematic representation of the sequential layers of interventions required to eliminate malaria from the most staunchly endemic regions of Africa, adapted from references [64] and [29]. White arrows crudely illustrate the impacts of intervention strategies for which reasonable experience and understanding already exists (suppression of high transmission with LLINs or IRS and elimination of sparse residual human parasite reservoirs with drugs). Dark arrows illustrate the potential impact of interventions that urgently need to be developed and evaluated to either maximize impact of existing control measures (adequate and sustainable financing, long-term resistance management) or make more meaningful progress towards elimination (programmatic-scale interruption of residual transmission by behaviourally resilient and/or resistant mosquitoes using novel vector control tools, possibly supplemented with vaccines or chemoprophylaxis). 
targeting the mosquito behaviours which enable it [8,26-30,34-41,50-55,67-73,75,80]. A very wide diversity of novel or improved strategies for controlling vectors of residual transmission is now emerging (Figure 12).

\section{Improving control of house-entering adult mosquitoes}

Perhaps the oldest proven means of preventing human exposure to malaria transmission is the modification of houses to prevent mosquitoes from entering them [86] and this time-honoured approach has recently proven successful even in impoverished African settings where housing quality is limited [87-89]. Alternatively, new emanatory products that release vapour-phase insecticides offer the opportunity to repel or kill mosquitoes that would otherwise enter houses and feed upon their occupants [51]. However, the potential for these approaches to interact antagonistically with existing IRS and LLIN interventions needs to be carefully examined [10,14,15,51]. It may also be possible to improve upon the efficacy of IRS and LLIN technologies with enhanced active ingredients and formulations, and insecticidal wall linings are also showing considerable promise [90-92]. However, merely enhancing and refining these conventional indoor control methods may not always address the fundamental behavioural reasons why they achieve little impact upon vectors like An. arabiensis, An. darlingi, An. nunetzovari (species B or C) and An. punctimacula that minimize contact with treated surfaces while resting or feeding indoors [19,39-41,47]. Nevertheless, it is encouraging that recent assessments of IRS with a new organophosphate against An. arabiensis in east Africa proved far more successful in the absence of LLINs [93] than with them [40,41], presumably because mosquitoes that have fed are far more inclined to rest in a treated house than those that have not. While exclusively community-level control of malaria transmission by killing mosquitoes after allowing them to feed upon humans is theoretically beneficial, it does raise significant practical and ethical concerns [14,55]. Fortunately, other approaches may also be feasible: the impact of both chemical and biological insecticides against An. arabiensis can be dramatically enhanced by physically obstructing their exit, rather than their entry, from houses or trap structures, particularly if the active ingredients are applied to the obstructed exit points [94-96]. A promising alternative approach is to provide oral formulations of systemic

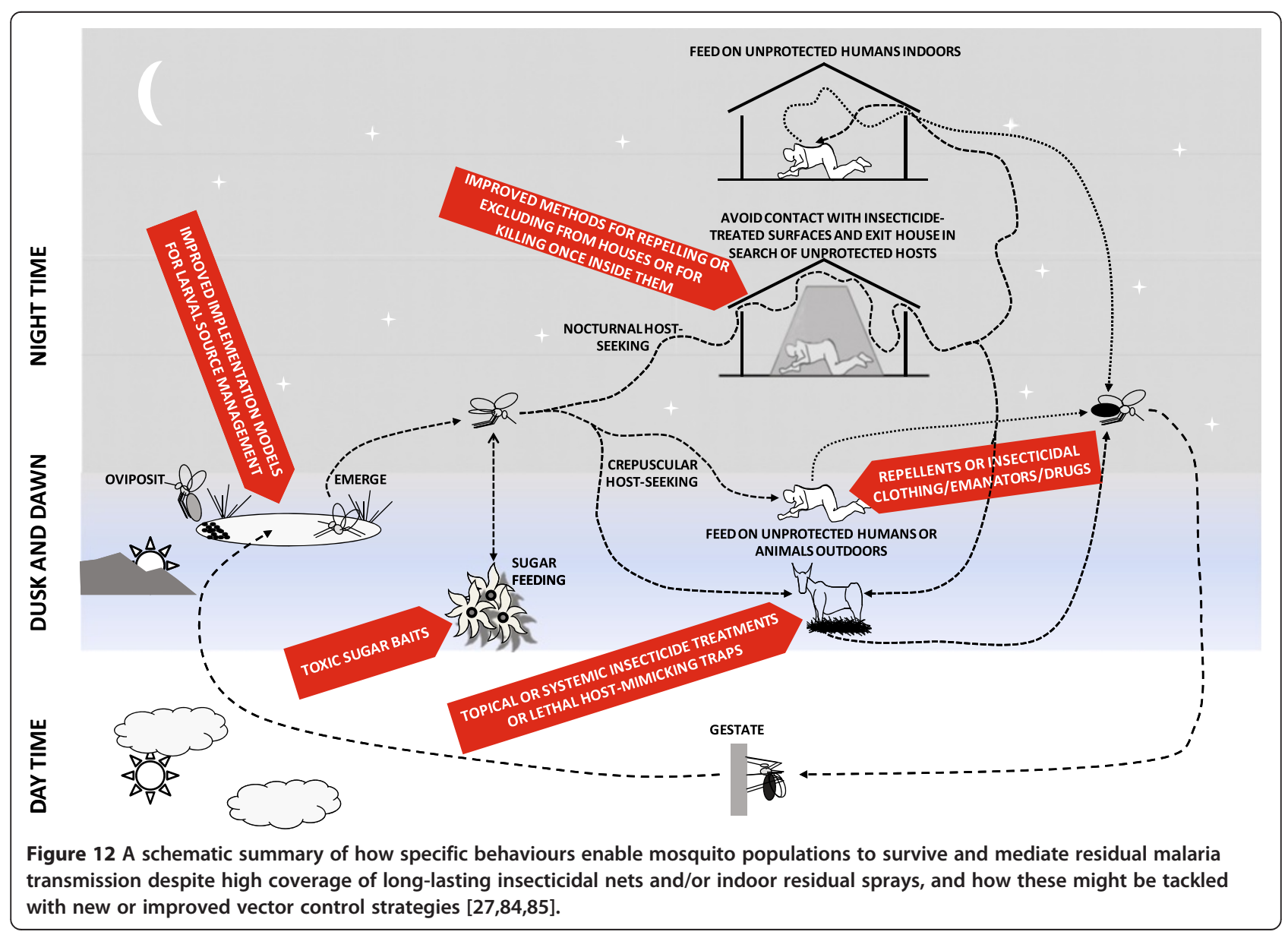


insecticides to humans to kill mosquitoes that feed upon them [97].

\section{Protecting humans against adult mosquitoes when they are active outdoors}

LLINs and insecticide-treated hammocks may readily be used to protect people sleeping outdoors but are obviously impractical when they are active [84]. The most obvious options for preventing outdoor exposure of humans, especially when they are active and cannot be practically enclosed within a structure like a net, include insecticidetreated clothes $[98,99]$ and repellents delivered as topical applications or vapour-phase emanators [51,100]. While such approaches to personal protection of people may achieve valuable community-wide impact upon transmission by simply reducing human-vector contact, they are unlikely to reduce the survival, density or vectorial capacity of the vector population where they obtain most of their blood from animals $[8,10,11]$ (Figure 13).

\section{Killing adult mosquitoes when they attack livestock}

Complementary approaches for killing mosquitoes when they feed upon animals, by treating livestock with topical [101] or systemic insecticides [97] may therefore be invaluable for tackling residual transmission through population control of zoophagic mosquitoes. Note, however, that great care should be taken to ensure the insecticide treatments used have a purely toxic mode of action and lack any irritant or repellent properties that could divert mosquitoes that would otherwise feed on animals to nearby humans [102]. Given that livestock owners primarily apply such veterinary products to protect the

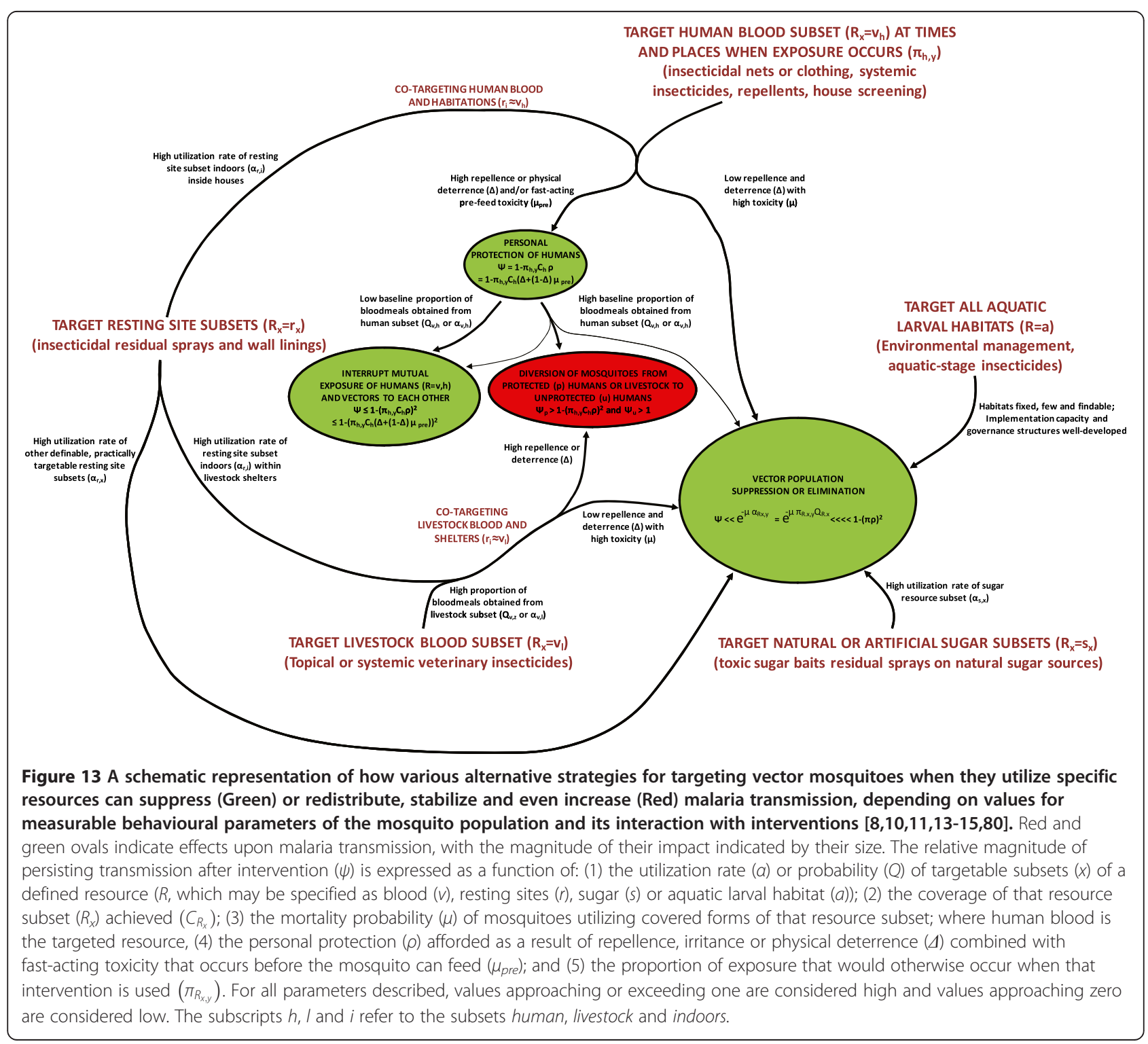


animals themselves, any potential for effective malaria vector control will require integration of malaria control priorities into agricultural practices, rather than vice versa.

\section{Killing adult mosquitoes when they feed upon sugar}

An exciting new approach to killing a wide diversity of vector species, regardless of their feeding or resting behaviours, is to treat natural or artificial sugar sources with insecticides [103-105]. The impressive impacts of toxic sugar baits upon three distinct vector species [103-105] are consistent with the high rates at which these mosquito populations utilize sugar $[80,106]$. Given the widespread dependence of mosquitoes upon sugar [107-109], especially when infected with malaria parasites [110], it appears that toxic sugar baits may be as generally effective [80] against a wide range of vectors as LLINs are against human-feeding vectors [21] and as insecticide-treated livestock are against animal-feeding vectors [101].

\section{Improving implementation systems for larval source management (LSM)}

The most direct way to control adult mosquitoes, especially those that are hard to kill because the exhibit various forms of behavioural evasiveness, is simply to prevent them from emerging in the first place. Immature egg, larval and pupal stages cannot fly so they are obviously unable to escape from physical modifications or insecticides applied directly to the aquatic habitats they live in [111]. LSM is perhaps the best established of all mosquito control strategies, with an impressive track record that was largely gained when it was the only mainstream malaria prevention strategy, before the advent of long-lasting adulticides prompted the shift to IRS, and then LLINs, as the highest priority intervention options [112,113]. Even more encouragingly, renewed investment in developing and evaluating such environmental management or larvicide application methods in Africa have yielded several examples of convincing success [89,112,113], leading to revised guidelines for implementation [114]. However, there have also been some examples where impact has been absent, limited or unclear and most successes have come from areas with medium-to-high human population density where aquatic habitats are relatively few, fixed and findable [89,112-114]. Indeed, seasonally-targeted LSM, implemented only when larval habitats contract to far more manageable levels in the dry season, may have a role to play in the final stages of eliminating malaria transmission $[29,36,115]$. However, it remains difficult to envisage how LSM strategies might be applied routinely and continuously in rural areas with sparse human populations, especially during the wet season peak of transmission when many areas are subject to flooding $[112,114]$. Furthermore, even where larval source management is clearly applicable in principle, rigorously evaluated models for effective programme implementation, monitoring, management and governance in contemporary tropical settings [116,117] remain scarce. Larval source management may have an important role to play in a wide variety of settings, and the implementation systems to deliver it are evolving, but its applicability in rural parts of the tropics will remain limited for the foreseeable future $[112,114]$ and much remains to be done in terms of defining how to establish and sustain effective programmes based on rigorous, quality-assured entomological surveillance [117-120].

\section{Learning how to tackle residual transmission with unproven vector control options}

There are numerous supplementary vector control options for tackling mosquitoes that persist and mediate residual transmission because they rest outdoors, feed outdoors or feed on animals (Figure 12), and these may be rationally selected based on local surveys of vector behaviours (Figure 13) [8,28,80]. However, none of these options have been developed and evaluated sufficiently to justify unreserved recommendation for national-scale roll out by NMCPs. In the absence of an adequate evidence base, NMCPs must either accept the limitations of IRS and LLINs by waiting for the research community to fill remaining knowledge gaps, or they must press ahead as best they can. A medium-to-long term strategy is clearly required to enable NMCPs and their scientific partners to define the needs, markets, ideal product characteristics and optimal delivery systems for such additional control tools through an adaptive learning process $[121,122]$. Given the considerable resource constraints that already restrict implementation of LLINs and IRS [123], and the limited evidence available to guide efforts to address residual transmission, perhaps the best way forward for NMCPs is to selectively incorporate supplementary vector control tools into exploratory, pilot-scale integrated vector management programmes [124] that evolve and expand as they establish their own supporting evidence base over the long term, just as the Onchocerciasis Control Programme did [125,126].

\section{Selecting complementary vector control methods by characterizing vector behaviours}

While the broad diversity and exciting potential of the options described in Figure 12 is encouraging, this also makes it difficult to select any one of them ahead of another. With limited resources, and a bewildering array of unproven methods for controlling behaviourally evasive vectors to choose from, NMCPs, together with their industrial and scientific partners, need to rationally select a 
small subset of these options to take forward for concerted programmatic development and evaluation [8,127]. The likelihood of success or failure of all the options described in Figure 12, are determined by measurable behaviours of mosquitoes and humans (Figure 13). The behavioural determinants of potential applicability and impact of LSM strategies can be reliably assessed with straightforward, well-established field procedures for surveying the distribution of productive habitat among different types of water bodies $[112,114]$. In the case of interventions that target blood resources, conceptual frameworks for their selection based on field measurements of vector behaviours, using well-established survey methods that may be readily incorporated into national surveillance platforms (Table 1), are now emerging [8]. This approach may also be extended to a wide variety of other targetable resources that mosquitoes need to survive (Figures 12 and 13), especially if entomological methods for measuring utilization rates for targetable resting sites can be improved $[8,80]$.

Many countries have now established surveillance platforms for monitoring physiological resistance to insecticides among nationally important vectors at selected sentinel sites [33]. However, the results of these simple insecticide susceptibility assays are not sufficient in themselves for NMCPs to rationally select and implement optimal vector control strategies. This is due to the fact that the small experimental enclosures and insectary rearing conditions they are conducted under are not representative of how wild mosquitoes interact with insecticides in the field. While there are examples of physiological resistance to insecticides resulting in intervention failure $[28,32,135,136]$, LLINs appear to provide valuable levels of personal protection against even highly pyrethroid-resistant vectors [137], and there are examples in which community-level transmission control has been maintained despite such resistance [138]. Several possible reasons for this have been outlined or even demonstrated [139-141]. The quantitative influence of mosquito behaviours upon the successes, limitations and failures of specific intervention strategies, even those as well-established as IRS and LLINs, remain uncertain. It is therefore essential that national entomological surveillance schemes now supplement routine surveys of physiological resistance with regular surveys of mosquito and human behaviours and of underlying resource use and livelihood patterns of those human populations $[8,28,142]$. Platforms for continuous longitudinal monitoring of vector population and malaria transmission dynamics will also be required at the same sentinel locations so that the relevance to programmatic decision-making of any worrying behavioural or physiological traits observed can be directly appraised (Figure 4) [28,31,33,121,142].

Unfortunately, the examples of well-characterized vector behaviours described in Figures 7 to 10 are merely static

\section{Table 1 A suggested generic plan for strengthening national or regional malaria vector monitoring platforms to incorporate assessment of essential behavioural phenotypes and their influence upon vector control impact, mosquito population dynamics and epidemiological outcomes $[8,28]$}

1. Expand and/or consolidate any existing national network of sentinel surveillance sites for physiological resistance of malaria vector mosquitoes to insecticides [33], ideally integrating these with similar platforms for other common mosquito-borne pathogens, such as lymphatic filariasis. Such sites should also overlap both with existing historical entomological study sites for which baseline legacy data is available, and with national platforms for assessing malaria burden through cross-sectional malaria indicator surveys or quality-assured facility-based surveillance.

2 Establish continuous longitudinal surveillance of mosquito population densities, and the transmission intensity each distinct population mediates, at sites where physiological resistance is monitored, so that the effects of vector control implementation upon seasonal and inter-annual trends can be assessed. Such surveillance platforms are essential to quantify residual transmission and distinguish between the fundamental limitations of an effective vector control strategy delivering incomplete but valuable and sustained impact versus an intervention failure, in the strict sense, which allows vector populations and malaria transmission to rebound (Figure 4) [28,29,31]. Such continuous, longitudinal surveys of malaria vector population dynamics have never been applied before at nationally representative scales. As such, affordable, practical community- or districtbased mosquito trapping schemes, which are nevertheless resourced and managed by centralized national programmes, may need to be developed and evaluated $[31,120]$. Given the reliance of scalable trapping schemes, especially those which are community-based, upon widely scattered, field-based personnel who may not always perform adequately $[118,119]$, it is also essential to establish quality assurance systems in which each of these sentinel sites is regularly and randomly re-surveyed by a centrally coordinated, specialist entomological team using the same trapping methods $[31,120]$. Given the diversity of vector species and behaviours across the tropics, setting up such platforms for monitoring mosquito population dynamics may require initial pilot evaluations to select and calibrate suitable trapping methods or validate calibrations from elsewhere.

3. Incorporate surveys of vector feeding and resting behaviours (using human landing catch by participants protected with drug chemoprophylaxis [128] and backpack aspirator/resting container/screening barrier sampling tools [129-131], respectively) into the quality assurance surveys described above under point 2, so that the extent to which each important vector species feeds on humans, feeds indoors, or rests indoors, can be quantified.

4. Integrate monitoring of relevant human behaviours [16] and ecology, including resource use and livelihoods, vector control coverage and livestock ownership into national malaria surveys and/or entomologic surveillance platforms, so that their contributions to intervention limitations and failures can be assessed.

5 Where substantial transmission occurs indoors, experimental hut [132-134] facilities should be established at one or two sentinel sites where the most nationally-relevant vector species are abundant, so that the efficacy of vector control interventions can be assessed before and after their introduction [39]. 
stereotypes that fail to capture the considerable variations that occur in behaviour within individual vector species, as a function of time, location and local intervention history. While behavioural variability has been documented for a wide diversity of other important vectors of residual malaria transmission $[26,53,73,142], A n$. arabiensis is a particularly good example with which to illustrate this point because it exhibits impressive variability in essentially all its relevant behaviours $[28,59,142]$. The proportion of blood meals it obtains from humans spans the whole range of possible values depending on how it responds opportunistically to fine scale variations in blood host availability [143]. While it feeds outdoors to a considerable degree in parts of Tanzania with high coverage of LLINs [50] or house screening [65,144], it persists with predominantly indoor feeding habits in parts of neighbouring Kenya with even longer-standing LLIN coverage [46]. Given the opportunity to feed within houses where the occupants lack LLINs, it does so and can be successfully targeted with IRS [93]. However, in stark contrast, it rapidly leaves houses where occupants use LLINs so that supplementary IRS consequently has little impact [39-41].

National and regional malaria control programmes will therefore need to carefully consider how, where and when they monitor important mosquito behaviours $[8,28,142]$. Thus far, even well established entomological methods for measuring vector behaviours have only been applied at village or district scale, and with inconsistent methodology and haphazard distribution across times and locations [2]. This is because they have been predominantly funded through sporadic, short-term research projects. These opportunistic, inconsistent and unreliable sources of vector behaviour measurements now need to be superseded by programmatically-funded, longitudinal monitoring systems operating consistently at national and regional scales (Table 1).

While routine monitoring of mosquito behaviours and population dynamics is essential to characterize and quantify intervention limitations and failures, it can also provide valuable explanatory evidence with which to bolster support for existing interventions like LLINs and IRS $[8,13,16,26,28,46,70,142]$. For example, the impressive recent demonstration of the massive impact of LLINs in a holoendemic Senegalese village where residents were provided with almost daily access to testing and treatment [145], is completely compatible with Figures 3, 7, 10 and 11. First, the observed impact on EIR, as measured by human landing catches, appears plausible (Figure 3) based on the expected level of biological coverage that would be achieved for the three vectors present (Figure 10), given that their human-feeding behaviour in this location [66] appears approximately consistent with most other reports for the same species from elsewhere in Africa (Figure 7).
Furthermore the EIR values reported after LLIN distribution were measured by fully exposed volunteers so de facto transmission levels experienced by protected residents were probably a further order of magnitude lower (Figure 7), reduced from $>100$ to $<1$ infectious bite per person per year and therefore consistent with the length of the upper white arrow in Figure 11. Given the ongoing challenge of sustaining funding support for provision of proven interventions like LLINs and IRS [123], it is essential that control programmes can access, interpret and disseminate such data routinely not only to understand and address their own shortcomings, but also to promote and sustain their successes $[8,16,28,142]$.

\section{Programmatic evaluation of new intervention options: learning by doing}

Where local circumstances allow, NMCPs may incorporate supplementary vector control approaches into exploratory programmes that should include strong monitoring, evaluation and operational research components in the same way that the Onchocerciasis Control Programme did $[125,126]$, initially through exploratory pilot assessments at manageable, sub-national scales. This strategy will minimize the cost of learning from mistakes along an uncertain route to an adequate evidence base and, eventually, to full-scale implementation. While randomizedcontrolled trials to evaluate intervention efficacy are of course invaluable contributions to the evidence base, evaluations of effectiveness under non-randomized programmatic conditions are often more relevant, representative and feasible for NMCPs [146].

While such ambitious, NMCP-led programmes for regularly monitoring, evaluating and targeting specific insect behaviours remain to be realized in relation to the vectors of malaria [121,122], the overwhelming historical success of black fly control by the regional Onchocerciasis Control Programme in West Africa [125,126] illustrates just how much may be accomplished with a similar strategy of practice-led research, rather than research-led practice. While this approach will undoubtedly take years of troubleshooting, this challenging developmental phase is also an exceptionally useful opportunity for "learning-bydoing". This substantial body of work will probably span at least a decade and represents a historic opportunity to strengthen and institutionalize national expertise through participation in operational research and evaluation at an advanced scientific, rather than merely technical, level. All such investments in these new programmatic monitoring platforms should, therefore, include substantive training components from the outset, especially at postgraduate and post-doctoral level. While a decade may seem like a long time for NMCPs struggling under difficult circumstances to deliver malaria control to huge at-risk populations, it represents the shortest possible period 
required to develop even a single individual scientist beyond the level of competence to real expertise [147]. Developing relevant expert human resources in the fields of vector biology, epidemiology, informatics, statistics and mathematical modelling will therefore require immediate, concerted and sustained investment in the capacity-strengthening opportunities presented by this extended, but obviously finite, phase of operational research. Crucially, such expert human capacity needs to be established under sustainable and appropriate conditions of ownership and governance at national institutions in malaria endemic countries $[121,122]$. While private and para-statal institutions like universities and research institutes have an important role to play, it is the governmental ministries and departments, including the NMCPs themselves, that must receive the highest priority for investing in capacity strengthening [121,122].

\section{Abbreviations}

EIR: Entomologic inoculation rate; GMEP: Global Malaria Eradication Programme; LLINs: Long-lasting insecticidal nets; LSM: Larval source management; IRS: Indoor residual spraying.

\section{Competing interests}

The author declares that he has no competing interests. The funder defined the study goal and objectives, and provided advisor input as well as editorial support, but had no role in the analysis or decision to publish the manuscript.

\section{Authors' contributions}

GFK drafted, edited and finalized the manuscript based on detailed discussions with a number of helpful colleagues who are acknowledged below.

\section{Acknowledgements}

I thank Jeffrey Hii, Martha Quiñones, Michael Reddy, Pierre Carnevale, Jonathan Lines, Josiane Etang, Pierre Guillet, Birkinesh Ameneshewa, Emmanuel Temu, Melanie Renshaw, Mark Rowland, Sharma Singh, Robert Wirtz, Joshua Yukich, Immo Kleinschmeidt, Jan Kolaczinski, Matthew Lynch, Michael MacDonald, Chioma N. Amajoh, Allan Schapira, Marianne Sinka, Patricia Graves, Maureen Coetzee, Alison Clements-Hunt, Abraham Mnzava and Marc Coosemans for invaluable discussions and comments on the manuscript. I also thank Fredros Okumu and Alex Limwagu for preparing the map presented in Figure 2, as well as Frank Smithuis, Nick White, Hugo Bugoro, Tanya Russell, Bernadette Huho, Olivier Briët, Aklilu Seyoum, Chadwick Sikaala, Nabie Bayoh, John Gimnig, Fredros Okumu, Diadier Diallo, Salim Abdulla and Tom Smith for sharing original data used to prepare Figures 7, 9 and 10. This work was funded by the World Health Organization (Contract reference 2013/345262-0).

Received: 30 May 2014 Accepted: 16 August 2014

Published: 23 August 2014

\section{References}

1. Service MW, Townson H: The Anopheles Vector. In Essential Malariology. Fourthth edition. Edited by Gilles HM, Warrell DA. London: Arnold; 2002:59-84.

2. Sinka ME, Bangs MJ, Manguin S, Rubio-Palis $Y$, Chareonviriyaphap T, Coetzee M, Mbogo CM, Hemingway J, Patil AP, Temperley WH, Gething PW, Kabaria CW, Burkot TR, Harbach RE, Hay SI: A global map of dominant malaria vectors. Parasit Vectors 2012, 5:69.

3. Beier JC: Malaria development in mosquitoes. Annu Rev Entomol 1998, 43:519-543.

4. Cohuet A, Harris C, Robert V, Fontenille D: Evolutionary forces on Anopheles: what makes a malaria vector? Trends Parasitol 2010, 26:130-136.
5. Guerra CA, Howes RE, Patil AP, Gething PW, Van Boeckel TP, Temperley WH, Kabaria CW, Tatem AJ, Manh BH, Elyazar IR, Baird JK, Snow RW, Hay SI: The international limits and population at risk of Plasmodium vivax transmission in 2009. PLoS Negl Trop Dis 2010, 4:e774.

6. Hay SI, Okiro EA, Gething PW, Patil AP, Tatem AJ, Guerra CA, Snow RW: Estimating the global clinical burden of Plasmodium falciparum malaria in 2007. PLoS Med 2010, 7:e1000290.

7. Kiswewski AE, Mellinger A, Spielman A, Malaney P, Sachs SE, Sachs J: A global index representing the stability of malaria transmission. Am J Trop Med Hyg 2004, 70:486-498.

8. Killeen GF, Seyoum A, Gimnig JE, Stevenson JC, Drakeley CJ, Chitnis N: Made-to-measure malaria vector control strategies: rational design based on insecticide properties and coverage of blood resources for mosquitoes. Malar J 2014, 13:146.

9. Killeen GF, Smith TA: Exploring the contributions of bednets, cattle, insecticides and excito-repellency to malaria control: A deterministic model of mosquito host-seeking behaviour and mortality. Trans $R$ Soc Trop Med Hyg 2007, 101:867-880.

10. Kiware SS, Chitnis N, Devine GJ, Moore SJ, Majambere S, Killeen GF: Biologically meaningful coverage indicators for eliminating malaria transmission. Biol Lett 2012, 8:874-877.

11. Kiware SS, Chitnis N, Moore SJ, Devine GJ, Majambere S, Killeen GF: Simplified models of vector control impact upon malaria transmission by zoophagic mosquitoes. PLoS One 2012, 7:e37661.

12. Le Menach A, Takala S, McKenzie FE, Perisse A, Harris A, Flahault A, Smith DL: An elaborated feeding cycle model for reductions in vectorial capacity of night-biting mosquitoes by insecticide-treated nets. Malar J 2007, 6:10,

13. Killeen GF, Seyoum A, Sikaala CH, Zomboko AS, Gimnig JE, Govella NJ, White MT: Eliminating malaria vectors. Parasit Vectors 2013, 6:172.

14. Killeen GF, Chitnis N, Moore SJ, Okumu FO: Target product profile choices for intra-domiciliary malaria vector control pesticide products: repel or kill? Malar J 2011, 10:207.

15. Killeen GF, Moore SJ: Target product profiles for protecting against outdoor malaria transmission. Malar J 2012, 11:17.

16. Huho BJ, Briët O, Seyoum A, Sikaala CH, Bayoh N, Gimnig JE, Okumu FO, Diallo D, Abdulla S, Smith TA, Killeen GF: Consistently high estimates for the proportion of human exposure to malaria vector populations occurring indoors in rural Africa. Int J Epidemiol 2013, 42:235-247.

17. Basseri HR, Abai MR, Raeisi A, Shahandeh K: Community sleeping pattern and anopheline biting in southeastern Iran: a country earmarked for malaria elimination. Am J Trop Med Hyg 2012, 87:499-503.

18. Charlwood JD, Graves PM, Alpers MP: The ecology of the Anopheles punctulatus group from Papua New Guinea: A review of recent work. Papua New Guinea Med J 1986, 29:19-26.

19. Elliott R: The influence of vector behaviour upon malaria transmission. Am J Trop Med Hyg 1972, 21:755-763.

20. Elliott R: Studies on man-vector contact in some malarious areas in Colombia. Bull World Health Organ 1968, 38:239-253.

21. Lengeler C: Insecticide-treated bed nets and curtains for preventing malaria. Cochrane Database Syst Rev 2004, 2:CD000363.

22. Pluess $B$, Tanser FC, Lengeler $C$, Sharp BL: Indoor residual spraying for preventing malaria. Cochrane Database Syst Rev 2010, 4:CD006657.

23. Killeen GF, Smith TA, Ferguson HM, Mshinda H, Abdulla S, Lengeler C, Kachur SP: Preventing childhood malaria in Africa by protecting adults from mosquitoes with insecticide-treated nets. PLoS Med 2007, 4:e229.

24. Moonen B, Cohen JM, Snow RW, Slutsker L, Drakeley C, Smith DL, Abeyasinghe RR, Rodriguez MH, Maharaj R, Tanner M, Targett G: Operational strategies to achieve and maintain malaria elimination. Lancet 2010, 376:1592-1603.

25. Smith DL, Cohen JM, Chiyaka C, Johnston G, Gething PW, Gosling R, Buckee CO, Laxminarayan R, Hay SI, Tatem AJ: A sticky situation: the unexpected stability of malaria elimination. Philos Trans R Soc Lond B Biol Sci 2013, 368:20120145.

26. Durnez $L$, Coosemans M: Residual transmission of malaria: an old issue for new approaches. In Anopheles mosquitoes - New insights into malaria vectors (Manguin. Sth edition. Rijeka: Intech; 2013:671-704.

27. Ferguson HM, Dornhaus A, Beeche A, Borgemeister C, Gottlieb M, Mulla MS, Gimnig JE, Fish D, Killeen GF: Ecology: a prerequisite for malaria elimination and eradication. PLoS Med 2010, 7:e1000303.

28. Govella NJ, Chaki PP, Killeen GF: Entomological surveillance of behavioural resilience and resistance in residual malaria vector populations. Malar J 2013, 12:124. 
29. Killeen GF: A second chance to tackle African malaria vector mosquitoes that avoid houses and don't take drugs. Am J Trop Med Hyg 2013, 88:809-816.

30. Russell TL, Beebe NW, Cooper RD, Lobo NF, Burkot TR: Successful malaria elimination strategies require interventions that target changing vector behaviours. Malar J 2013, 12:56.

31. Sikaala CH, Chinula D, Chanda J, Hamainza B, Mwenda M, Mukali I, Kamuliwo M, Lobo NF, Seyoum A, Killeen GF: A cost-effective, community-based, mosquito-trapping scheme that captures spatial and temporal heterogeneities of malaria transmission in rural Zambia. Malar J 2014, 13:225.

32. Cohen JM, Smith DL, Cotter C, Ward A, Yamey G, Sabot OJ, Moonen B: Malaria resurgence: a systematic review and assessment of its causes. Malar J 2012, 11:122.

33. WHO Global Malaria Control Programme: Global plan for insecticide resistance management in malaria vectors (GPIRM). Geneva: World Health Organization; 2012:130

34. Govella NJ, Ferguson HM: Why use of interventions targetting outdoor biting mosquitoes will be necessary to achieve malaria elimination. Front Physiol 2012, 3:199.

35. Griffin JT, Hollingsworth TD, Okell LC, Churcher TS, White M, Hinsley W Bousema T, Drakeley CJ, Ferguson NM, Basáñez MG, Ghani AC: Strategies towards Plasmodium falciparum malaria elimination in Africa using currently available tools. PLoS Med 2010, 7:e1000324.

36. Eckhoff PA: Mathematical models of within-host and transmission dynamics to determine effects of malaria interventions in a variety of transmission settings. Am J Trop Med Hyg 2013, 88:817-827.

37. Briët OJ, Chitnis N: Effects of changing mosquito host searching behaviour on the cost effectiveness of a mass distribution of longlasting, insecticidal nets: a modelling study. Malar J 2013, 12:215.

38. Killeen GF, Chitnis N: Potential causes and consequences of behavioural resilience and resistance in malaria vector populations: a mathematical modelling analysis. Malar J 2014, 13:97.

39. Kitau J, Oxborough RM, Tungu PK, Matowo J, Malima RC, Magesa SM, Bruce J, Mosha F, Rowland MW: Species shifts in the Anopheles gambiae complex: do LLINs successfully control Anopheles arabiensis? PLOS One 2012, 7:e31481.

40. Okumu FO, Kiware SS, Moore SJ, Killeen GF: Mathematical evaluation of community level impact of combining bed nets and indoor residual spraying upon malaria transmission in areas where the main vectors are Anopheles arabiensis mosquitoes. Parasit Vectors 2013, 6:17.

41. Okumu FO, Mbeyela E, Ligamba G, Moore J, Ntamatungiro AJ, Kavishe DR, Kenward MG, Turner E, Lorenz LM, Moore SJ: Comparative evaluation of combinations of long lasting insecticidal nets and indoor residual spraying, relative to either method alone, for malaria vector control in an area dominated by Anopheles arabiensis. Parasit Vectors 2013, 6:46.

42. Muirhead-Thomson RC: Mosquito behaviour in relation to malaria transmission and control in the tropics. London: Edward Arnold \& Co.; 1951.

43. Muirhead-Thomson RC: The significance of irritability, behaviouristic avoidance and allied phenomena in malaria eradication. Bull World Health Organ 1960, 22:721-734

44. Kouznetsov RL: Malaria control by application of indoor spraying of residual insecticides in tropical Africa and its impact on community health. Trop Doct 1977, 7:81-93.

45. Bayoh MN, Mathias DK, Odiere MR, Mutuku FM, Kamau L, Gimnig JE, Vulule JM, Hawley WA, Hamel MJ, Walker ED: Anopheles gambiae: historical population decline associated with regional distribution of insecticidetreated bed nets in western Nyanza Province, Kenya. Malar J 2010, 9:62.

46. Bayoh MN, Walker ED, Kosgei J, Ombok M, Olang GB, Githeko AK, Killeen GF, Otieno P, Desai M, Lobo NF, Vulule JM, Hamel MJ, Kariuki S, Gimnig JE: Persistently high estimates of late night, indoor exposure to malaria vectors despite high coverage of insecticide treated nets. Parasit Vectors 2014, 7:380.

47. Habtewold T, Prior A, Torr SJ, Gibson G: Could insecticide-treated cattle reduce Afrotropical malaria transmission? Effects of deltamethrin-treated Zebu on Anopheles arabiensis behaviour and survival in Ethiopia. Med Vet Entomol 2004, 18:408-417.

48. Derua YA, Alifrangis M, Hosea KM, Meyrowitsch DW, Magesa SM, Pedersen EM, Simonsen PE: Change in composition of the Anopheles gambiae complex and its possible implications for the transmission of malaria and lymphatic filariasis in north-eastern Tanzania. Malar J 2012, 11:188.

49. Mwangangi JM, Mbogo CM, Orindi BO, Muturi EJ, Midega JT, Nzovu J, Gatakaa H, Githure J, Borgemeister C, Keating J, Beier JC: Shifts in malaria vector species composition and transmission dynamics along the Kenyan coast over the past 20 years. Malar J 2013, 12:13.

50. Russell TL, Govella NJ, Azizi S, Drakeley CJ, Kachur SP, Killeen GF: Increased proportions of outdoor feeding among residual malaria vector populations following increased use of insecticide-treated nets in rural Tanzania. Malar J 2011, 10:80.

51. Achee NL, Bangs MJ, Farlow R, Killeen GF, Lindsay S, Logan JG, Moore SJ, Rowland M, Sweeney K, Torr SJ, Zwiebel LJ, Grieco JP: Spatial repellents: from discovery and development to evidence-based validation. Malar $J$ 2012, 11:164.

52. WHO: Guidelines for efficacy testing of spatial repellents. Geneva: World Health Organization; 2013.

53. Pates $\mathrm{H}$, Curtis $\mathrm{C}$ : Mosquito behavior and vector control. Annu Rev Entomol 2005, 50:53-70.

54. Grieco JP, Achee NL, Chareonviriyaphap T, Suwonkerd W, Chauhan K, Sardelis MR, Roberts DR: A new classification system for the actions of IRS chemicals traditionally used for malaria control. PLoS One 2007, 2:e716.

55. Yakob L, Dunning R, Yan G: Indoor residual spray and insecticide-treated bednets for malaria control: theoretical synergisms and antagonisms. $J$ R Soc Interface 2011, 8:799-806.

56. Grieco JP, Achee NL, Sardelis MR, Chauhan K, Roberts DR: A novel high throughput screening system to evaluate the behavioral responses of adult mosquitoes to chemicals. J Am Mosq Control Assoc 2005, 21:404-411.

57. Lyimo IN, Ferguson HM: Ecological and evolutionary determinants of host species choice in mosquito vectors. Trends Parasitol 2009, 25:189-196.

58. Gillies MT, Coetzee M: A supplement to the Anophelinae of Africa South of the Sahara (Afrotropical region). Johannesburg: South African Medical Research Institute; 1987.

59. White GB: Anopheles gambiae complex and disease transmission in Africa. Trans R Soc Trop Med Hyg 1974, 68:279-301.

60. Hasan AU, Suguri S, Fujimoto C, Itaki RL, Harada M, Kawabata M, Bugoro H, Albino B, Tsukahara T, Hombhanje F, Masta A: Phylogeography and dispersion pattern of Anopheles farauti senso stricto mosquitoes in Melanesia. Mol Phylogenet Evol 2008, 46:792-800.

61. Beebe NW, Cooper RD: Distribution and evolution of the Anopheles punctulatus group (Diptera: Culicidae) in Australia and Papua New Guinea. Int J Parasitol 2002, 32:563-574.

62. Beier JC, Killeen GF, Githure J: Short report: Entomologic inoculation rates and Plasmodium falciparum malaria prevalence in Africa. Am J Trop Med Hyg 1999, 61:109-113.

63. Smith DL, Dushoff J, Snow RW, Hay Sl: The entomological inoculation rate and Plasmodium falciparum infection in African children. Nature 2005, 438:492-495.

64. Smith DL, McKenzie FE, Snow RW, Hay SI: Revisiting the basic reproductive number for malaria and its implications for malaria control. PLOS Biol 2007, 5:e42.

65. Govella NJ, Okumu FO, Killeen GF: Insecticide-treated nets can reduce malaria transmission by mosquitoes which feed outdoors. Am J Trop Med Hyg 2010, 82:415-419.

66. Trape JF, Tall A, Diagne N, Ndiath O, Ly AB, Faye J, Dieye-Ba F, Roucher C, Bouganali C, Badiane A, Sarr FD, Mazenot C, Toure-Balde A, Raoult D, Druilhe P, Mercereau-Puijalon O, Rogier C, Sokhna C: Malaria morbidity and pyrethroid resistance after the introduction of insecticide-treated bednets and artemisinin-based combination therapies: a longitudinal study. Lancet Infect Dis 2011, 11:925-932.

67. Yohannes M, Boelee E: Early biting rhythm in the afro-tropical vector of malaria, Anopheles arabiensis, and challenges for its control in Ethiopia. Med Vet Entomol 2012, 26:103-105.

68. Moiroux N, Gomez MB, Pennetier C, Elanga E, Djènontin A, Chandre F, Djègbé I, Guis H, Corbel V: Changes in Anopheles funestus biting behaviour following universal coverage of long-lasting insecticidal nets in Benin. J Infect Dis 2012, 206:1622-1629.

69. Sougoufara S, Diedhiou SM, Doucoure S, Diagne N, Sembene PM, Harry M Trape JF, Sokhna C, Ndiath MO: Biting by Anopheles funestus in broad daylight after use of long-lasting insecticidal nets: a new challenge to malaria elimination. Malar J 2014, 13:125.

70. Moiroux N, Damien GB, Egrot M, Djenontin A, Chandre F, Corbel V, Killeen GF, Pennetier C: Human exposure to early morning Anopheles funestus biting behavior and personal protection provided by Long-Lasting Insecticidal Nets. PLoS One 2014, 9:e104967.

71. Killeen GF, Kihonda J, Lyimo E, Okech FR, Kotas ME, Mathenge E, Schellenberg J, Lengeler C, Smith TA, Drakeley C: Quantifying behavioural 
interactions between humans and mosquitoes: Evaluating the protective efficacy of insecticidal nets against malaria transmission in rural Tanzania. BMC Infect Dis 2006, 6:161.

72. Seyoum A, Sikaala $\mathrm{CH}$, Chanda J, Chinula D, Ntamatungiro AJ, Hawela M, Miller JM, Russell TL, Briët OJT, Killeen GF: Most exposure to Anopheles funestus and Anopheles quadriannulatus in Luangwa valley, South-East Zambia occurs indoors, even for users of insecticidal nets. Parasit Vectors 2012, 5:101.

73. Obsomer V, Defourny P, Coosemans M: The Anopheles dirus complex: spatial distribution and environmental drivers. Malar J 2007, 6:26.

74. Smith Gueye C, Newby G, Hwang J, Phillips AA, Whittaker M, MacArthur JR, Gosling RD, Feachem RG: The challenge of artemisinin resistance can only be met by eliminating Plasmodium falciparum malaria across the Greater Mekong subregion. Malar J 2014, 13:286.

75. Bugoro H, Cooper RD, Butafa C, Iro'ofa C, Mackenzie DO, Chen CC, Russell TL: Bionomics of the malaria vector Anopheles farauti in Temotu Province, Solomon Islands: issues for malaria elimination. Malar J 2011, 10:133.

76. Vythilingam I, Sidavong B, Chan ST, Phonemixay T, Vanisaveth V, Sisoulad P, Phetsouvanh R, Hakim SL, Phompida S: Epidemiology of malaria in Attapeu Province, Lao PDR in relation to entomological parameters. Trans R Soc Trop Med Hyg 2005, 99:833-839.

77. Smithuis FM, Kyaw MK, Phe UO, van der Broek I, Katterman N, Rogers C, Almeida P, Kager PA, Stepniewska K, Lubell Y, Simpson JA, White NJ: The effect of insecticide-treated bed nets on the incidence and prevalence of malaria in children in an area of unstable seasonal transmission in western Myanmar. Malar J 2013, 12:363.

78. Smithuis FM, Kyaw MK, Phe UO, van der Broek I, Katterman N, Rogers C, Almeida P, Kager PA, Stepniewska K, Lubell Y, Simpson JA, White NJ: Entomological determinants of insecticide-treated bed net effectiveness in Western Myanmar. Malar J 2013, 12:364

79. Dev V, Sharma VP: The dominant mosquito vectors of human malaria in India. In Anopheles moquitoes-New insights into new malaria vectors. Edited by Manguin S. Rijeka, Croatia: InTech; 2013:239-271.

80. Killeen GF, Kiware SS, Seyoum A, Gimnig JE, Corliss G, Stevenson JC, Drakeley CJ, Chitnis N: Comparative assessment of diverse strategies for malaria vector population control based on measured rates at which mosquitoes utilize targeted resource subsets. Malar J 2014, 13:338.

81. Ulrich JN, Naranjo DP, Alimi TO, Muller GC, Beier JC: How much vector control is needed to achieve malaria elimination? Trends Parasitol 2013, 29:104-109.

82. Zoghi S, Mehrizi AA, Raeisi A, Haghdoost AA, Turki H, Safari R, Kahanali AA, Zakeri S: Survey for asymptomatic malaria cases in low transmission settings of Iran under elimination programme. Malar J 2012, 11:126.

83. Abeyasinghe RR, Galappaththy GN, Smith Gueye C, Kahn JG, Feachem RG: Malaria control and elimination in Sri Lanka: documenting progress and success factors in a conflict setting. PLoS One 2012, 7:e43162.

84. Rozendaal JA: Vector Control. Methods for use by individuals and communities. Geneva: WHO; 1997.

85. The malERA Consultative Group on Vector Control: A research agenda for malaria eradication: vector control. PLOS Med 2011, 8:e1000401.

86. Lindsay SW, Emerson PM, Charlwood JD: Reducing malaria transmission by mosquito-proofing homes. Trends Parasitol 2002, 18:510-514.

87. Kirby MJ, Ameh D, Bottomley C, Green C, Jawara M, Milligan PJ, Snell PC, Conway DJ, Lindsay SW: Effect of two different house screening interventions on exposure to malaria vectors and on anaemia in children in The Gambia: a randomised controlled trial. Lancet 2009, 374:998-1009.

88. Maheu-Giroux M, Castro MC: Do malaria vector control measures impact disease-related behaviour and knowledge? Evidence from a large-scale larviciding intervention in Tanzania. Malar J 2013, 12:422.

89. Maheu-Giroux M, Castro MC: Impact of community-based larviciding on the prevalence of malaria infection in Dar es Salaam, Tanzania. PLoS One 2013, 8:e71638.

90. Lindblade KA: Does a mosquito bite when no-one is around to hear it? Int J Epidemiol 2013, 42:247-249.

91. Messenger LA, Matias A, Manana AN, Stiles-Ocran JB, Knowles S, Boakye DA, Coulibaly MB, Larsen M-L, Traoré AS, Diallo B, Konaté M, Guindo A, Traoré SF, Mulder CEG, Le H, Kleinschmidt I, Rowland M: Multicentre studies of insecticide-treated durable wall lining in Africa and South-East Asia: entomological efficacy and household acceptability during one year of field use. Malar J 2012, 11:358.
92. Messenger LA, Miller NP, Adeogun AO, Awolola TS, Rowland M: The development of insecticide-treated durable wall lining for malaria control: insights from rural and urban populations in Angola and Nigeria. Malar J 2012, 11:332

93. Oxborough RM, Kitau J, Jones R, Feston E, Matowo J, Mosha FW, Rowland MW: Long-lasting control of Anopheles arabiensis by a single spray application of micro-encapsulated pirimiphos-methyl (Actellic(R) 300 CS). Malar J 2014, 13:37.

94. Okumu FO, Madumla EP, John AN, Lwetoijera DW, Sumaye RD: Attracting, trapping and killing disease-transmitting mosquitoes using odor-baited stations - The Ifakara Odor-Baited Stations. Parasit Vectors 2010, 3:12.

95. Lwetoijera DW, Sumaye RD, Madumla EP, Kavishe DR, Mnyone LL, Russell TL, Okumu FO: An extra-domiciliary method of delivering entomopathogenic fungus, Metharizium anisopliae IP 46 for controlling adult populations of the malaria vector, Anopheles arabiensis. Parasit Vectors 2010, 3:18.

96. Mnyone LL, Lyimo IN, Lwetoijera DW, Mpingwa MW, Nchimbi N, Hancock PA, Russell TL, Kirby MJ, Takken W, Koenraadt CJ: Exploiting the behaviour of wild malaria vectors to achieve high infection with fungal biocontrol agents. Malar J 2012, 11:87.

97. Chaccour CJ, Kobylinski KC, Bassat Q, Bousema T, Drakeley C, Alonso P, Foy $\mathrm{BD}$ : Ivermectin to reduce malaria transmission: a research agenda for a promising new tool for elimination. Malar J 2013, 12:153.

98. Macintyre K, Sosler S, Letipila F, Lochigan M, Hassig S, Omar SA, Githure J: A new tool for malaria prevention? Results of a trial of permethrinimpregnated bedsheets (shukas) in an area of unstable transmission. Int J Epidemiol 2003, 32:157-160.

99. Kimani EW, Vulule JM, Kuria IW, Mugisha F: Use of insecticide-treated clothes for personal protection against malaria: a community trial. Malar J 2006, 5:63.

100. Ogoma SB, Ngonyani H, Simfukwe ET, Mseka A, Moore J, Killeen GF: Spatial repellency of transfluthrin-treated hessian strips against laboratoryreared Anopheles arabiensis mosquitoes in a semi-field tunnel cage. Parasit Vectors 2012, 5:54

101. Rowland M, Durrani N, Kenward M, Mohammed N, Urahman H, Hewitt S: Control of malaria in Pakistan by applying deltamethrin insecticide to cattle: a community-randomised trial. Lancet 2001, 357:1837-1841.

102. Saul A: Zooprophylaxis or zoopotentiation: the outcome of introducing animals on vector transmission is highly dependent on the mosquito mortality while searching. Malar J 2003, 2:32.

103. Müller G, Schlein Y: Sugar-questing mosquitoes in arid areas gather on scarce blossoms that can be used for control. Int J Parasitol 2006, 36:1077-1080.

104. Müller G, Schlein Y: Efficacy of toxic sugar baits against cistern-dwelling Anopheles claviger. Trans R Soc Trop Med Hyg 2008, 102:480-484.

105. Müller GC, Beier JC, Traore SF, Toure MB, Traore MM, Bah S, Doumbia S, Schlein $Y$ : Successful field trial of attractive toxic sugar bait (ATSB) plant-spraying methods against malaria vectors in the Anopheles gambiae complex in Mali, West Africa. Malar J 2010, 9:210.

106. Marshall JM, White MT, Ghani AC, Schlein Y, Muller GC, Beier JC: Quantifying the mosquito's sweet tooth: modelling the effectiveness of attractive toxic sugar baits (ATSB) for malaria vector control. Malar 2013, 12:291.

107. Gu W, Muller G, Schlein Y, Novak RJ, Beier JC: Natural plant sugar sources of Anopheles mosquitoes strongly impact malaria transmission potential. PLoS One 2011, 6:e15996.

108. Huestis DL, Yaro AS, Traore Al, Adamou A, Kassogue Y, Diallo M, Timbine S, Dao A, Lehmann T: Variation in metabolic rate of Anopheles gambiae and A. arabiensis in a Sahelian village. J Exp Biol 2011, 214:2345-2353.

109. Foster WA: Mosquito sugar feeding and reproductive energetics. Annu Rev Entomol 1995, 40:443-474.

110. Nyasembe VO, Teal PE, Sawa P, Tumlinson JH, Borgemeister C, Torto B: Plasmodium falciparum infection increases Anopheles gambiae attraction to nectar sources and sugar uptake. Curr Biol 2014, 24:217-221.

111. Killeen GF, Fillinger U, Knols BGJ: Advantages of larval control for African malaria vectors: Low mobility and behavioural responsiveness of immature mosquito stages allow high effective coverage. Malar J 2002, $1: 8$

112. Fillinger $U$, Lindsay SW: Larval source management for malaria control in Africa: myths and reality. Malar J 2011, 10:353.

113. Tusting LS, Thwing J, Sinclair D, Fillinger U, Gimnig J, Bonner KE, Bottomley C, Lindsay SW: J. G., Bonner KE, Bottomley C, Lindsay SW: Mosquito larval 
source management for controlling malaria. Cochrane Database Syst Rev 2013, 8:CD008923.

114. WHO: Larval source management-A supplementary measure for malaria vector control: An Operational Manual. Geneva: World Health Organization; 2013.

115. The malERA Consultative Group on Drugs: A research agenda for malaria eradication: drugs. PLoS Med 2011, 8:e1000402.

116. Fillinger U, Kannady K, William G, Vanek MJ, Dongus S, Nyika D, Geissbuehler Y, Chaki PP, Govella NJ, Mathenge EM, Singer BH, Mshinda $\mathrm{H}_{\text {, }}$ Lindsay SW, Tanner M, Mtasiwa D, de Castro MC, Killeen GF: A tool box for operational mosquito larval control: preliminary results and early lessons from the Urban Malaria Control Programme in Dar es Salaam, Tanzania. Malar J 2008, 7:20.

117. Chaki PP, Kannady K, Mtasiwa D, Tanner M, Mshinda H, Kelly AH, Killeen GF: Institutional evolution of a community-based programme for malaria control through larval source management in Dar es Salaam, United Republic of Tanzania: A case study. Malar J 2014, 13:245.

118. Chaki PP, Dongus S, Kannady K, Fillinger U, Kelly A, Killeen GF: CommunityOwned Resource Persons for malaria vector control: enabling factors and challenges in an operational programme in Dar es Salaam, Tanzania. Human Res Health 2011, 9:21.

119. Chaki PP, Govella NJ, Shoo B, Hemed A, Tanner M, Fillinger U, Killeen GF: Achieving high coverage of larval-stage mosquito surveillance: challenges for a community-based mosquito control programme in urban Dar es Salaam, Tanzania. Malar J 2009, 8:311.

120. Chaki PP, Mlacha Y, Msellemu D, Muhili A, Malishee AD, Mtema ZJ, Kiware S, Russell TL, Zhou Y, Lobo N, Dongus S, Govella NJ, Killeen GF: An affordable, quality-assured community-based system for high resolution entomological surveillance of vector mosquitoes that reflects human malaria infection risk patterns. Malar J 2012, 11:172.

121. WHO: Vector Control Technical Expert Group Report to MPAC for September 2013-Capacity Building in Entomology and Vector Control. Geneva: Global Malaria Programme, World Health Organization; 2013:17.

122. WHO: Guidance note on capacity building in malaria entomology and vector control. Geneva: Global Malaria Programme, World Health Organization; 2013:3.

123. WHO: World Malaria Report 2013. Geneva: World Health Organization; 2013.

124. WHO: Global Strategic Framework for Integrated Vector Management. Geneva: World Health Organization; 2004

125. Hougard JM, Yameogo L, Seketeli A, Boatin B, Dadzie KY: Twenty-two years of blackfly control in the onchocerciasis control programme in West Africa. Parasitol Today 1997, 13:425-431.

126. Remme JH: Research for control: the onchocerciasis experience. Trop Med Int Health 2004, 9:243-254.

127. Vontas J, Moore SJ, Kleinschmidt I, Ranson H, Lindsay SW, Lengeler C, Hamon N, McLean T, Hemingway J: Framework for rapid assessment and adoption of new vector control tools. Trend Parasitol 2014, 30:191-204.

128. Gimnig JE, Walker ED, Otieno P, Kosgei J, Olang G, Ombok M, Williamson J, Marwanga D, Abongo D, Desai M, Kariuki S, Hamel MJ, Lobo NF, Vulule J, Bayoh $\mathrm{MN}$ : Incidence of malaria among mosquito collectors conducting human landing catches in Western Kenya. Am J Trop Med Hyg 2013, 88:301-308.

129. Odiere M, Bayoh MN, Gimnig J, Vulule J, Irungu L, Walker E: Sampling outdoor resting Anopheles gambiae and other mosquitoes (Diptera: Culicidae) in Western Kenya with clay pots. J Med Entomol 2007, 44:14-22.

130. Maia MF, Robinson A, John AN, Mgando J, Simfukwe E, Moore SJ: Comparison of the CDC Backpack aspirator and the Prokopack aspirator for sampling indoor- and outdoor-resting mosquitoes in southern Tanzania. Parasit Vectors 2011, 4:124.

131. Burkot TR, Russell TL, Reimer L, Bugoro H, Beebe NW, Cooper RD, Sukawati S, Collins FH, Lobo NF: Barrier screens: a method to sample blood-fed and host-seeking exophilic mosquitoes. Malar J 2013, 12:49.

132. Okumu FO, Moore J, Mbeyela E, Sherlock M, Sangusangu R, Ligamba G, Russell T, Moore SJ: A modified experimental hut design for studying responses of disease-transmitting mosquitoes to indoor interventions: the Ifakara experimental huts. PLoS One 2012, 7:e30967.

133. Silver JB, Service MW: Mosquito ecology: field sampling methods. 3rd edition. Dordrecht, the Netherlands: Springer; 2008.

134. WHO: Guidelines for testing mosquito adulticides for indoor residual spraying and treatment of mosquito nets. Geneva, Switzerland: World Health Organization; 2006.

135. Aikpon R, Agossa F, Osse R, Oussou O, Aizoun N, Oke Agbo F, Akogbeto M: Bendiocarb resistance in Anopheles gambiae s.l. populations from
Atacora department in Benin, West Africa: a threat for malaria vector control. Parasit Vectors 2013, 6:192.

136. Osse RA, Aikpon R, Gbedjissi GL, Gnanguenon V, Sezonlin M, Govoetchan R, Sovi A, Oussou O, Oke-Agbo F, Akogbeto M: A shift from Indoor Residual Spraying (IRS) with bendiocarb to Long-Lasting Insecticidal (mosquito) Nets (LLINs) associated with changes in malaria transmission indicators in pyrethroid resistance areas in Benin. Parasit Vectors 2013, 6:73.

137. Strode C, Donegan S, Garner P, Enayati AA, Hemingway J: The impact of pyrethroid resistance on the efficacy of insecticide-treated bed nets against African anopheline mosquitoes: systematic review and meta-analysis. PLoS Med 2014, 11:e1001619.

138. Hemingway J, Vontas J, Poupardin R, Raman J, Lines J, Schwabe C, Matias A, Kleinschmidt I: Country-level operational implementation of the Global Plan for Insecticide Resistance Management. Proc Natl Acad Sci U S A 2013, 110:9397-9402.

139. Ferguson HM, Maire N, Takken W, Lyimo IN, Briet O, Lindsay SW, Smith TA: Selection of mosquito life-histories: a hidden weapon against malaria? Malar J 2012, 11:106

140. Jones CM, Sanou A, Guelbeogo WM, Sagnon N, Johnson PC, Ranson H: Aging partially restores the efficacy of malaria vector control in insecticide-resistant populations of Anopheles gambiae s.l. from Burkina Faso. Malar J 2012, 11:24.

141. Ranson H, N'Guessan R, Lines J, Moiroux N, Nkuni Z, Corbel V: Pyrethroid resistance in African anopheline mosquitoes: what are the implications for malaria control? Trends Parasitol 2011, 27:91-98.

142. Gatton ML, Chitnis N, Churcher T, Donnelly MJ, Ghani AC, Godfray HC, Gould F, Hastings I, Marshall J, Ranson H, Rowland M, Shaman J, Lindsay SW: The importance of mosquito behavioural adaptations to malaria control in Africa. Evolution 2013, 67:1218-1230.

143. Killeen GF, McKenzie FE, Foy BD, Bogh C, Beier JC: The availability of potential hosts as a determinant of feeding behaviours and malaria transmission by mosquito populations. Trans R Soc Trop Med Hyg 2001, 95:469-476.

144. Geissbuhler Y, Chaki P, Emidi B, Govella NJ, Shirima R, Mayagaya V, Mtasiwa D, Mshinda H, Fillinger U, Lindsay SW, Kannady K, de Castro MC, Tanner M Killeen GF: Interdependence of domestic malaria prevention measures and mosquito-human interactions in urban Dar es Salaam, Tanzania. Malar J 2007, 6:126.

145. Trape JF, Tall A, Sokhna C, Ly AB, Diagne N, Ndiath O, Mazenot C, Richard V, Badiane A, Dieye-Ba F, Faye J, Ndiaye G, Diene Sarr F, Roucher C, Bouganali C, Bassene H, Tour Balde A, Roussilhon C, Perraut R, Spiegel A, Sarthou JL, da Silva LP, Mercereau Puijalon O, Druilhe P, Rogier C: The rise and fall of malaria in a West African rural community, Dielmo, Senegal, from 1990 to 2012: a 22 year longitudinal study. Lancet Infect Dis 2014, 14:476-488.

146. Habicht JP, Victora CG, Vaughan JP: Evaluation designs for adequacy, plausibility and probability of public health programme performance and impact. Int J Epidemiol 1999, 28:10-18.

147. Doumbo OK, Krogstad DJ: Doctoral training of African scientists. Am J Trop Med Hyg 1998, 58:127-132.

\section{doi:10.1186/1475-2875-13-330}

Cite this article as: Killeen: Characterizing, controlling and eliminating residual malaria transmission. Malaria Journal 2014 13:330.

\section{Submit your next manuscript to BioMed Central and take full advantage of:}

- Convenient online submission

- Thorough peer review

- No space constraints or color figure charges

- Immediate publication on acceptance

- Inclusion in PubMed, CAS, Scopus and Google Scholar

- Research which is freely available for redistribution 